\title{
Release of exosomes and microvesicles harbouring specific RNAs and glycosylphosphatidylinositol-anchored proteins from rat and human adipocytes is controlled by histone methylation
}

\author{
Günter Müller*, Marion Schneider, Johann Gassenhuber, Susanne Wied
}

Diabetes Division, Research \& Development, Sanofi Deutschland GmbH, Frankfurt am Main, Germany

Email: "guenter.mueller@sanofi.com

Received 14 March 2012; revised 19 April 2012; accepted 18 May 2012

\begin{abstract}
The transfer of proteins and nucleic acids from donor to acceptor cells via small membrane vesicles has been implicated with (patho)physiological consequences. Previously the upregulation of esterification and downregulation of lipolysis in small rat adipocytes upon incubation with exosomes and microvesicles (EMVs) released from large adipocytes and harbouring the glycosylphosphatidylinositol (GPI)-anchored proteins, Gce1 and CD73, transcripts specific for FSP27 and GPAT3, and microRNAs, miR-16 and miR-222 were demonstrated. Here the release of EMVs from large (but not small) primary rat and differentiated rat and human adipocytes in response to palmitate, $\mathrm{H}_{2} \mathrm{O}_{2}$ and the anti-diabetic sulfonylurea, glimepiride, is shown to be significantly reduced upon inhibition of histone H3 lysine9 methyltransferase G9a by trans-2-phenylcyclopropylamine (tPCPA) and histone H3 lysine4 demethylase LSD1 by BIX01294. Inhibition of EMV release by tPCPA and BIX01294 was not caused by apoptosis but accompanied by upregulation of the $\mathrm{H}_{2} \mathrm{O}_{2}$-induced stimulation of lipid synthesis and downregulation of lipolysis in large (but not small) primary and differentiated rat and human adipocytes. In contrast, the simultaneous presence of TPCPA and BIX01294 had almost no effect on the induced release of EMVs and lipid metabolism. These findings argue for regulation of the release of EMVs harbouring specific GPI-anchored proteins, transcripts and microRNAs from rat and human adipocytes by histone $\mathrm{H3}$ methylation at lysines 4 and 9 in interdependent fashion. Thus the EMV-mediated transfer of lipogenic and anti-lipolytic information between large and small adipocytes in response to certain physiological and pharmacological stimuli seems to be controlled by epigenetic mechanisms.
\end{abstract}

"Corresponding author.
Keywords: cAMP; Epigenetic Control; Exosomes; Glimepiride; Glycosylphosphatidylinositol; Lipid Metabolism; Microparticles; miRNA; Microvesicles

\section{INTRODUCTION}

The increased prevalence of obesity in present day society and the current view of adipose tissue as one of the most critical regulators of energy homeostasis and metabolism have warranted a sustained interest in studying the mechanisms controlling its formation. The (post) transcriptional cascade governing adipogenesis, i.e. the differentiation of adipocytes from precursor cells and their subsequent maturation from small unilocular (i.e. containing many small lipid droplets [LD]) to large multilocular (i.e. containing few large LDs) cells has been extensively studied for many years [1]. Novel findings suggest the involvement of small membrane vesicles in the control of maturation of rodent adipocytes within adipose tissue depots in vitro [2-7]. Moreover, small membrane vesicles were reported to be increased in the serum of obese women compared to normal age-matched controls and suggested to account for the increased risk of thrombotic complications during obesity $[8,9]$.

Small membrane vesicles have been known for decades to be released from most animal cell types [10,11]. They have the same topology as the donor cell, are of variable diameter $(50-1000 \mathrm{~nm})$ and mediate the secretion of a wide variety of proteins, phospholipids, mRNAs and microRNAs (miRNAs). The mechanisms underlying the biogenesis of small membrane vesicles remain unclear at the moment. According to current models released membrane vesicles either bud directly from the plasma membrane resulting in so-called microvesicles, or bud into endosomes to form multivesicular bodies followed by their fusion with the plasma membrane resulting in so-called exosomes $[10,12]$. However, the differ- 
entiation between microvesicles and exosomes turned out to be problematic due to the lack of unambigous physical properties or molecular markers and, in consequence, the impossibility to know the cellular origin of any particular released vesicle. Furthermore, a number of experimental observations are difficult to reconcile with a strict separation between microvesicle and exosome biogenesis (see DISCUSSION). Given these uncertainties it has recently been suggested to use the collective acronym, EMVs, for exosomes plus microvesicles [13] for any released small membrane vesicle that is also used in the following.

Most importantly, EMVs may interact with neighbouring cells and can thereby transmit signals encoded by their constituent components from cell to cell $[12,14,15]$. In particular, vesicle-derived mRNAs and miRNAs may alter gene expression in neighbouring cells upon release of EMVs from donor cells and subsequent fusion with acceptor cells along a non-viral pathway of intercellular vesicle trafficking and thereby play important roles in physiological processes as well as disease states, such as cancer $[16,17]$. Indeed, it has recently been shown that certain tumors shed EMVs, which are rich in signalling molecules and genetic material that together constitute a specific and readily identifiable signature [10]. Moreover, miRNAs entrapped in EMVs are detectable in the serum of cancer patients by qRT-PCR (quantitative real-time polymerase chain reaction) in tumor-specific fashion $[14$, $18]$.

miRNAs have also been recognized as regulators of metabolic integration, energy homeostasis and adipocyte differentiation, presumably since each single species of them manages to simultaneously control a large number of target genes [19-24]. For instance, the expression of 50 out of 70 miRNAs was found to significantly differ between human pre- or mature adipocytes from lean and obese individuals [23]. Moreover, EMVs released from cultured 3T3-L1 adipocytes have been reported to harbour about 140 miRNAs [4]. The majority of them were adipocyte-specific, abundant in correlation with their expression level in the donor cells and considerably upregulated during adipocyte differentiation in vitro. Interestingly, these apparently adipocyte-derived EMVs also seem to mediate the transport of mRNAs coding for adiponectin, resistin and PPAR $\gamma$ into cultured macrophages $[3,4]$ and to induce angiogenesis [4]. In addition, adipocyte-specific mRNAs and miRNAs have also been detected in EMVs isolated from rat serum $[4,23]$.

Recently, the release of EMVs from primary and cultured rat and mouse adipocytes has been demonstrated to undergo considerable upregulation upon challenge with physiological stimuli, such as fatty acids (palmitate) and reactive oxygen species $\left(\mathrm{H}_{2} \mathrm{O}_{2}\right)$, as well as pharmacological agents, such as the anti-diabetic drug, glimepiride
[25-28]. These adipocyte-derived EMVs are thought to regulate lipid metabolism between large and small adipocytes within the same adipose tissue depot in course of the transfer of (some of) their constituent components. Among them are the glycosylphosphatidylinositol (GPI)anchored cAMP-specific phosphodiesterase, Gce1, and 5'-nucleotidase, CD73, that catalyze (c)AMP degradation [29-31], the mRNAs coding for glycerol-3-phosphate acyltransferase-3 (GPAT3) and fat-specific protein-27 (FSP27), that drive lipid synthesis and LD biogenesis, respectively [32-34], as well as the miRNAs, miR-16 and miR-222, that have been implicated to coordinate lipid metabolic pathways [19-22]. The underlying mechanisms encompass: 1) the release of those EMVs from preferentially large donor adipocytes, 2) the interaction of those EMVs with preferentially small acceptor adipocytes, 3) the translocation of Gce1 and CD73 from the (lipid rafts of the) EMV membranes to intracellular LDs of the acceptor adipocytes as well as the delivery of the GPAT3- and FSP27-encoding mRNAs and the miR-16/ 222 from the EMV lumen to the cytoplasm of the acceptor adipocytes, 4) the degradation of (c)AMP at the LD surface zone by Gce1 and CD73 and finally 5) the upregulation of fatty acid esterification at the LDs and downregulation of fatty acid release from the LDs by concerted action of GPAT3, FSP27, lowered cAMP levels and miR-16/222 in the acceptor adipocytes [5-7,2429]. These findings suggested that EMVs transfer lipogenic and anti-lipolytic information from large to small adipocytes to shift the burden of lipid loading within adipose tissue depots during certain (patho)physiological states [31]. Among them are excessive fatty acid intake, anti-diabetic pharmacotherapy or exposure to cellular oxidative stress, that may all accompany or foster the obese state.

Up to now, obesity has been studied predominantly from a thermoenergetic point of view, taking into consideration the balance between energy intake and expenditure determined by gene mutations and polymorphisms and the lifestyle. The putative involvement of epigenetic mechanisms, i.e. inheritable alterations in gene expression that are established in the absence of a change in the DNA sequence itself, in the development of obesity has only recently begun to attract attention $[35,36]$. The underlying molecular mechanisms include covalent posttranslational modifications of the histone tails [37,38], with lysine methylation resulting in enhancing or silencing of the transcriptional state of a given gene depending on the modified residue. In particular, methylation of lysine 4 of histone $\mathrm{H} 3$ (H3K4) usually correlates with gene activation, whereas methylation of lysine 9 of histone $\mathrm{H} 3(\mathrm{H} 3 \mathrm{~K} 9)$ is associated with transcriptional silencing [39].

With regard to obesity an adverse environment during 
in utero or lactation periods is generally assumed to affect its future development, suggesting that the mother's nutrition or perinatal lifestyle choices could alter the developmental programming of the foetus and pubs [35]. In contrast, the role of adverse environment (e.g. nutrition, cellular stress, pharmacotherapy) during adulthood in the modification of the epigenetic pattern is still a matter of debate. Thus changes in the histone methylation patterns could be a result of the interplay of various dietary and environmental factors and provide a source of inter-individual differences with respect to the susceptibility to develop obesity [40].

Albeit some miRNAs have been attributed critical functions in the epigenetic control of adipogenesis and obesity [19,20,41], and other miRNAs have been recovered with EMVs released from adipocytes and circulating in various body fluids [4,24], experimental evidence for the involvement of EMVs as putative carriers for epigenetic information between somatic cells in para- or endocrine fashion has not been reported so far. However, the recent findings of the regulation of cell size and lipid metabolism between large and small rat adipocytes by EMVs harbouring specific GPI-anchored proteins, mRNAs and miRNAs raised the possibility that their release or fusion in response to certain environmental stimuli is under epigenetic control. The present study demonstrates that in course of long-term incubation with inhibitors of either $\mathrm{H} 3 \mathrm{~K} 9$ methylation or $\mathrm{H} 3 \mathrm{~K} 4$ demethylation, the palmitate-, glimepiride- and $\mathrm{H}_{2} \mathrm{O}_{2}$-induced release of EMVs harbouring Gce1/CD73 proteins, GPAT3/FSP27encoding mRNAs and miR-16/222 miRNAs from large primary and differentiated rat and human adipocytes is significantly reduced.

\section{MATERIALS AND METHODS}

\subsection{Reagents}

tPCPA (tranylcypromine = trans-2-phenylcyclopropylamine hydrochloride) was purchased from ArborAssays (Ann Arbor, USA). BIX-01294 (2,4-diamino-6,7-dimethoxyquinazoline) was provided by Tocris Biosciences (Bristol, UK). Trapoxin A (cyclo-(L)-phenylalanyl-(L)phenylalanyl-(D)-2-amino-8-oxo-9,10-epoxy-decanoyl) was delivered by Sigma-Aldrich (Deisenhofen, Germany). CCT077791 (N-substituted isothiazolone derivative) was from Merck-Calbiochem (Darmstadt, Germany). SAHA (vorinostat $=$ suberoylanilide hydroxamic acid) was bought from Cayman Chemicals (Ann Arbor, USA). Antibodies against CD73 (recombinant, murine) were obtained from USBiological (Massachusetts, USA). Primers were purchased from TIB Molbiol (Berlin, Germany). Human insulin [42] and glimepiride [43] were produced by Sanofi Deutschland GmbH (Frankfurt, Germany). Glucose oxidase (GO), RNase inhibitor ("Pro- tector", recombinant, from lung) and protease inhibitor cocktail ("cOmplete ULTRA" tablets) were provided by Roche Biochemicals (Mannheim, Germany). All other materials were purchased as described previously [25-31, 44-47].

\subsection{Animal Handling}

All experimental procedures were conducted in accordance with the German Animal Protection Law and corresponded to international animal welfare legislation and rules. The male rats (Sprague-Dawley or Wistar, as indicated) were housed two per cage in an environmentally controlled room with a 12:12-hour light-dark circle (light on at 06:00 pm) and ad libitum access to water and standard rat chow as described previously [24,48].

\subsection{Preparation and Primary Culture of Rat Adipocytes}

Adipocytes were prepared under sterile conditions by collagenase digestion of epididymal fat pads isolated from male Sprague-Dawley rats [49], collected by flotation $\left(200 \mathrm{~g}, 2 \mathrm{~min}, 30^{\circ} \mathrm{C}\right)$, then filtered through serial nylon mesh screens to obtain small (diameter $<75 \mu \mathrm{m}$ from 1-month [120 - $140 \mathrm{~g}]$ old rats) and large (diameter $>400 \mu \mathrm{m}$ from 6-months [320 - $400 \mathrm{~g}$ ] old rats) adipocytes, respectively, and finally adjusted to $1 \times 10^{6} \mathrm{cells} / \mathrm{ml}$ with adipocyte buffer $(140 \mathrm{mM} \mathrm{NaCl}, 4.7 \mathrm{mM} \mathrm{KCl}, 2.5$ $\mathrm{mM} \mathrm{CaCl}_{2}, 1.2 \mathrm{mM} \mathrm{MgSO} 4,1.2 \mathrm{mM} \mathrm{KH} \mathrm{PO}_{4}, 20 \mathrm{mM}$ Hepes/KOH, pH 7.4) supplemented with $0.5 \%$ bovine serum albumin (BSA), $100 \mu \mathrm{g} / \mathrm{ml}$ gentamycin, 50 units $/ \mathrm{ml}$ penicillin and $50 \mu \mathrm{g} / \mathrm{ml}$ streptomycin sulfate.

For long-term incubation in primary culture according to previously published protocols $[50,51]$ with modifications, $100 \mu \mathrm{l}\left(\sim 10^{5}\right.$ cells $)$ portions of adipocytes were inoculated in $2 \mathrm{ml}$ of DMEM/F12 (1:1) containing 20\% fetal calf serum (FCS) in a collagen-coated 12-well plate (Nalge Nunc International, Rochester, USA) and covered with a sterile $20 \times 20 \mathrm{~mm}$ coverslip. Cells were incubated $\left(10-14\right.$ days, $\left.37^{\circ} \mathrm{C}\right)$ in a $5 \% \mathrm{CO}_{2}$-incubator depending on their attachment efficiency. Attachment efficiency to the ceiling surface of the coverslips varied between $50 \%$ and $80 \%$. Cell viability was checked by exclusion of trypan blue and was $>85 \%$ at the end of incubation. Adipocytes maintained their unilocular characteristics with multiple small LD emerging at the periphery (as assessed by Oil Red staining) upon challenge with palmitate, glimepiride or GO and further incubation, which was indicative for stimulation of lipid synthesis.

\subsection{Preparation and Differentiation of Rat Stromal Vascular Cells (SVCs)}

Rat SVCs were prepared by collagenase (250 units $/ \mathrm{ml}$, type II, Worthington, St Katharinen, Germany) digestion $\left(1 \mathrm{~h}, 37^{\circ} \mathrm{C}\right)$ of epididymal fat pads ( $\sim 5 \mathrm{~g}$ pieces) isolated 
from male Wistar rats (200 - $240 \mathrm{~g}, 9$ - 11 weeks old) in PBS containing $2 \%$ BSA. After filtration through a strainer, the digested adipose tissue was centrifuged (500 $\mathrm{g}, 10 \mathrm{~min}, 20^{\circ} \mathrm{C}$ ). The pellet was suspended in $10 \mathrm{ml}$ of adipocyte buffer and then passed through a $150 \mu \mathrm{m}$ mesh for removal of clumps and debris. The pass-through was centrifuged $\left(500 \mathrm{~g}, 10 \mathrm{~min}, 20^{\circ} \mathrm{C}\right)$. The pellet was suspended in $50 \mathrm{ml}$ of erythrocyte lysis buffer $(155 \mathrm{mM}$ $\mathrm{NH}_{4} \mathrm{Cl}, 5.7 \mathrm{mM} \mathrm{K}_{2} \mathrm{HPO}_{4}, 0.1 \mathrm{mM}$ EDTA in water) and then consecutively filtered through nylon mesh screens with pore sizes of 75 and $30 \mu \mathrm{m}$. The latter pass-through was centrifuged $\left(500 \mathrm{~g}, 10 \mathrm{~min}, 20^{\circ} \mathrm{C}\right)$. The pelleted SVCs were washed once, recentrifuged and then suspended in adipocyte buffer supplemented with $100 \mu \mathrm{g} / \mathrm{ml}$ gentamycin, 50 units $/ \mathrm{ml}$ penicillin and $50 \mu \mathrm{g} / \mathrm{ml}$ streptomycin at $3.5 \times 10^{6}$ cells $/ \mathrm{ml}$.

For differentiation into adipocytes, the SVCs were plated in duplicate onto circular coverglasses inserted in 12-well plates and cultured in DMEM-Ham's F-12 (1:1) containing $10 \%$ FCS, $100 \mu \mathrm{M}$ ascorbic acid, $33 \mu \mathrm{M}$ biotin, $17 \mu \mathrm{M}$ pantothenate, $25 \mathrm{nM}$ insulin, $50 \mathrm{nM}$ triiodothyronine, $2.5 \mathrm{mM}$ niacinamide and $1 \mu \mathrm{M}$ octanoic acid for 5 days. Subsequently the incubation was continued in adipogenic medium (DMEM/Ham's F10, 3\% FCS, 33 $\mu \mathrm{M}$ biotin, $17 \mu \mathrm{M}$ pantothenate, $25 \mathrm{nM}$ insulin, $1 \mu \mathrm{M}$ dexamethasone) supplemented with $0.2 \mathrm{mM}$ isobutylmethylxanthine, $10 \mathrm{nM}$ L-thyroxine and $0.1 \mu \mathrm{M}$ rosiglitazone) for the first 3 days and then in adipogenic medium for the following 9 days. Cells were used upon $80 \%$ - 90\% differentiation according to Oil Red staining and light microscopy.

\subsection{Preparation and Differentiation of Human Adipocytes}

Human MSCs (mesenchymal stem cells) between passages 4 and 10 (Cambrex BioScience, Verviers, Belgium) derived from resection of abdominal subcutaneous (external to the fascia superficialis, mesenteric and omental) fat tissue (2 - $10 \mathrm{~g}$ per subject) during gastric bypass surgery for the management of obesity $(29-61$ years, body mass index of $54 \pm 2 \mathrm{~kg} / \mathrm{m}^{2}$, fasting blood glucose lower than $120 \mathrm{mg} \%$, no malignancies, no administration of thiazolidinediones and steroids) were seeded in 12well plates at a density of $4 \times 10^{4}$ cells $/ \mathrm{cm}^{2}$ and incubated in DMEM/Ham's F12 (1:1, Invitrogen, Basel, Switzerland) containing $0.5 \%$ BSA and antibiotics for 3 days and then grown in MSC basal medium (Cambrex) until confluency (medium change every 2 days). Macrophages were rare $\left(<10\right.$ per $10^{6}$ cells $)$ as assessed by phase-contrast microscopy.

For differentiation from confluence, $1^{\text {st }}$ - to $4^{\text {th }}$-passage cells were differentiated using a previously described method $[52,53]$ with the following modifications: cul- tures were incubated (15 - 20 days) in 6-well plates in DMEM/Ham's F12 (1:1) containing 0.5\% BSA, 3\% FCS, antibiotics and the following supplements until completion of differentiation: $250 \mu \mathrm{M}$ isobutylmethylxanthine (removed after 2 days), $1 \mu \mathrm{M}$ dexamethasone, $0.2 \mathrm{nM}$ 3,3,5-triiodo-L-thyronine, $5 \mu \mathrm{M}$ transferrin (Sigma, Deisenhofen, Germany), $500 \mathrm{nM}$ human insulin and $1 \mu \mathrm{M}$ rosiglitazone (GlaxoSmithKline, Worthing, UK). Medium was changed every 2 days. 2 - 4 days after completion of differentiation, the cells were washed three times with warm PBS and used for the experiments. Differentiation of MSCs into adipocytes was considered to be successful in case of detection of 1) doubly refractile inclusions by low-power phase-contrast microscopy, that displayed LD nature according to staining with Oil Red $\mathrm{O}$, 2) expression of the adipocyte-specific mRNAs, PPAR $\gamma 2$, leptin, adiponectin and GLUT4 by qRT-PCR, and 3) isoproterenol $(1 \mu \mathrm{M})$-induced glycerol release and insulin (100 nM)-stimulated glucose transport.

\subsection{Metabolic Labeling of Adipocytes}

After incubation in the absence or presence of inhibitors, the differentiated adipocytes in 6-well plates were washed twice with $1 \mathrm{ml} /$ well of labeling medium (glucose-free DMEM containing $10 \%$ FCS, $0.2 \%$ BSA and $1 \mathrm{mM}$ sodium pyruvate) supplemented with $25 \mu \mathrm{g} / \mathrm{ml}$ gentamycin, $50 \mathrm{units} / \mathrm{ml}$ penicillin and $20 \mu \mathrm{g} / \mathrm{ml}$ streptomycin sulfate and then incubated $\left(2 \mathrm{~h}, 37^{\circ} \mathrm{C}\right)$ in $1 \mathrm{ml} /$ well of labeling medium under $95 \% \mathrm{O}_{2} / 5 \% \mathrm{CO}_{2}$ under gentle shaking. Labeling was started by the addition of $m y o-\left[\mathrm{U}-{ }^{14} \mathrm{C}\right]-$ inositol $(2.5 \mu \mathrm{Ci}$ in $1 \mathrm{ml}$ of labeling medium, $0.1 \mathrm{mM}$ final conc.). After incubation (2 h or 15-min "pulse" as indicated, $37^{\circ} \mathrm{C}$ ) the adipocytes were washed once with 1 $\mathrm{ml}$ of labeling medium lacking $m y o-\left[\mathrm{U}_{-}{ }^{14} \mathrm{C}\right]$ inositol and supplemented with $100 \mathrm{mM}$ myo-inositol and further incubated $\left(14 \mathrm{~h}\right.$ or $1 \mathrm{~h}$ "chase" as indicated, $\left.37^{\circ} \mathrm{C}\right)$.

\subsection{Preparation of EMVs}

After induction $\left(14 \mathrm{~h}, 37^{\circ} \mathrm{C}\right)$ of the primary or differentiated adipocytes in 12-well plates filled with $1 \mathrm{ml}$ per well of DMEM containing $5.5 \mathrm{mM}$ glucose, $10 \%$ FCS, $0.2 \%$ BSA, $1 \mathrm{mM}$ sodium pyruvate, $25 \mu \mathrm{g} / \mathrm{ml}$ gentamycin, 50 units $/ \mathrm{ml}$ penicillin and $20 \mu \mathrm{g} / \mathrm{ml}$ streptomycin sulfate by the addition of palmitate, glimepiride or GO (for the production of $\mathrm{H}_{2} \mathrm{O}_{2}$ in the glucose-containing incubation medium) to final concentrations as indicated, the cells were chilled. Primary adipocytes were collected by spinning ( $200 \mathrm{~g}, 3 \mathrm{~min}$ ). Total EMVs were prepared from the incubation medium ( $0.9 \mathrm{ml}$ portions) by two sequential passages through $5 \mu \mathrm{m}$ meshes to remove residual cells. The flow-through was supplemented with DTT (final conc. $0.5 \mathrm{mM}$ ) and protease inhibitor mix "complete" (final conc. 1 tablet per $100 \mathrm{ml}$ ), then centri- 
fuged $\left(1000 \mathrm{~g}, 10 \mathrm{~min}, 4^{\circ} \mathrm{C}\right)$ and finally filtered through $1 \mu \mathrm{m}$ PVDF meshes to remove residual cell debris. The flow-through was centrifuged $\left(2000 \mathrm{~g}, 20 \mathrm{~min}, 4^{\circ} \mathrm{C}\right)$. The resulting supernatant was re-centrifuged $(5000 \mathrm{~g}, 30 \mathrm{~min}$, $4^{\circ} \mathrm{C}$ ). From the resulting supernatant total EMVs were collected by centrifugation (Beckman Airfuge, A-110 fixed-angle rotor, $\left.110,000 \mathrm{rpm}, 1 \mathrm{~h}, 4^{\circ} \mathrm{C}\right)$. After careful aspiration of the supernatants, the pellets were suspended in $100 \mu \mathrm{l}$ of EMV buffer ( $10 \mathrm{mM}$ Tris- $\mathrm{HCl}, \mathrm{pH}$ 7.4, 250 $\mathrm{mM}$ sucrose, $1 \mathrm{mM}$ EDTA, $0.5 \mathrm{mM}$ EGTA, $140 \mathrm{mM}$ $\mathrm{NaCl}, 10 \mathrm{mM} \mathrm{MgCl} 2,2 \mathrm{mM} \mathrm{MnCl} 2,1 \mathrm{mM}$ DTT, protease inhibitor mix "complete"). For affinity purification of Gce1-/CD73-harbouring EMVs, total EMVs were adsorbed to cAMP- or AMP-Sepharose beads. For this, 100 $\mu 1$ of EMV suspension was supplemented with $200 \mu$ l of (c)AMP-Sepharose beads $(50 \mathrm{mg}$ in $1 \mathrm{ml}$ of $100 \mathrm{mM}$ Hepes-KOH, pH 7.4, $140 \mathrm{mM} \mathrm{NaCl}, 1 \mathrm{mM} \mathrm{MgCl} 2,0.5$ $\mathrm{mM}$ DTT and protease inhibitor mix "complete") and then incubated under continuous head-over rotation (60 cycles per min) of the tubes. Thereafter, the incubation mixtures were centrifuged $\left(500 \mathrm{~g}, 5 \mathrm{~min}, 4^{\circ} \mathrm{C}\right)$. The collected Sepharose bead-EMV complexes were washed twice and then suspended in $100 \mu$ l of EMV buffer containing either $100 \mu \mathrm{M}$ AMP or cAMP for dissociation of the EMVs from the beads. After incubation $\left(30 \mathrm{~min}, 4^{\circ} \mathrm{C}\right)$ and centrifugation $\left(5000 \mathrm{~g}, 5 \mathrm{~min}, 4^{\circ} \mathrm{C}\right)$, the supernatant was recovered and centrifuged (Beckman Airfuge, A-110 fixed-angle rotor, $110,000 \mathrm{rpm}, 30 \mathrm{~min}, 4^{\circ} \mathrm{C}$ ) for collection of the Gce1- or CD73-harbouring EMVs.

\subsection{RNA Isolation and $q R T-P C R$}

For the removal of exogenously adherent nucleic acids, the EMV pellets were suspended in $1 \mu \mathrm{g}$ RNase A (DNaseand protease-free; Roche Biochemicals, Mannheim, Germany) and DNase I (RNase-free; Qiagen, Hilden, Germany) per ml of EMV buffer and then incubated (1 h, $25^{\circ} \mathrm{C}$ ). The samples were centrifuged (Beckman Airfuge, A-110 fixed-angle rotor, $110,000 \mathrm{rpm}, 1 \mathrm{~h}, 4^{\circ} \mathrm{C}$ ), then suspended in EMV buffer containing RNase inhibitor (1 $\mathrm{U} / \mathrm{ml}$ ) and finally washed by three resuspension/washing cycles with $1 \mathrm{ml}$ of EMV buffer each. The washed EMV pellets were disintegrated by the use of Trizol (Invitrogen, Carlsbad, USA). Total RNA was isolated with the Qiagen (Hilden, Germany) RNeasy kit including proteinase $\mathrm{K}$ digestion, DNase digestion and an additional RNeasy cleanup step, as recommended by the manufacturer. Total RNA $(1 \mu \mathrm{g})$ was reverse-transcribed using appropriate primer sets. The specific transcripts were quantitatively evaluated as described previously [24].

\subsection{Statistical Analysis}

All values are expressed as means \pm S.D. as indicated in the figure legends. Statistical analysis was performed using Graphpad Prism software. Statistical significance between two incubation conditions was calculated with a two-tailed Student's $t$ test. A $P$-value of less than 0.05 was considered statistically significant.

\subsection{Miscellaneous}

Published procedures were used for determination of apoptosis as activation of cell-associated caspase 3 and 7 with fluorescence as read-out according to the manufacturer's instructions (apoptosis kit Promega), assaying of lipid synthesis by the incorporation of $\left[3-{ }^{3} \mathrm{H}\right]$ glucose $(0.2$ $\mu \mathrm{Ci} / \mathrm{ml}, 100 \mu \mathrm{M}$ ) into total acylglycerols (measured as radioactivity in toluene-based scintillation cocktail after partitioning of total scraped adipocytes) for $1 \mathrm{~h} \mathrm{[54]} \mathrm{and}$ of isoproterenol $(0.1 \mu \mathrm{M})$-induced lipolysis as the release of glycerol into the incubation medium (fluorometric detection) for $2 \mathrm{~h}$ [55], preparation and protein extraction under non-denaturing conditions of plasma membranes and LDs from primary rat adipocytes $[30,46]$, affinitypurification of CD73 and Gce1 from extracted plasma membrane and LD proteins [47], and protein determination [45]. For SDS-PAGE and phosphorimaging according to reported methods [45], equivalent amounts of EMVs, plasma membranes and LDs corresponding to the same number of cells were used.

\section{RESULTS}

Epigenetic histone methylation that dynamically transforms specific gene promoters into an open/active (euchromatic) or condensed/repressed (heterochromatic) conformation $[37,38,56]$ are catalyzed by histone methyltransferases and demethylases [57,58]. Two key chromatin marks are histone $\mathrm{H} 3$ mono/dimethyl-lysine 4 (H3K4me1/2), which is subject to demethylation by lysinespecific demethylase 1, LSD1 [59,60], and histone H3 dimethyl-lysine 9 (H3K9me2), which is mediated by the dimethylating histone methyltransferase, G9a [61]. G9a was found to be inhibited by the (1H-1,4-diazepin-1-yl)quinazolin-4-yl amine derivative, BIX01294, that is related to the $\alpha$-adrenoceptor antagonist bunazosin, in a reversible, uncompetitive (to the co-substrate S-adenosyl-methionine) and selective (toward other histone methyltransferases) manner [62]. LSD1, an amine oxidase using a FAD-dependent oxidative reaction mechanism, was demonstrated to be inhibited by the cyclopropylamine analog and monoamine oxidase inhibitor, tPCPA (tranylcypromine), in an irreversible (as suicide inactivator) fashion [63]. According to commercially available northern blotting data both G9a and LSD1 are expressed in rat and human adipose tissues as well as in differentiated human adipocytes to considerable extent (Table 1). Interestingly, differentiated adipocytes and adipose tissues prepared from obese humans and visceral fat depots of rats displayed slightly elevated G9a and LSD1 mRNA 
Table 1. Relative expression levels (arbitrary units) of G9a and LSD1 in various tissues and cultured adipocytes according to northern blotting data. Data are expressed as means \pm S.D.

\begin{tabular}{clcc}
\hline \multirow{2}{*}{ Species } & \multicolumn{1}{c}{ Tissue/Cell Line } & Relative Expression & LSD1 \\
\cline { 3 - 4 } Human & Adipose Non-Obese & $79.95 \pm 30.12$ & $159.05 \pm 16.98$ \\
& Adipose Obese & $101.85 \pm 28.34$ & $204.06 \pm 43.48$ \\
& Liver Non-Obese & $23.73 \pm 9.23$ & $141.72 \pm 30.56$ \\
& Liver Obese & $45.40 \pm 5.19$ & $169.14 \pm 14.00$ \\
& Skeletal Muscle Non-Obese & $40.52 \pm 21.56$ & $229.16 \pm 31.23$ \\
& Skeletal Muscle Obese & $43.05 \pm 13.23$ & $259.65 \pm 10.00$ \\
& Heart Ventricle Non-Obese & $26.80 \pm 8.24$ & $205.66 \pm 22.45$ \\
& Hippocampus Non-Obese & $181.64 \pm 32.10$ & $201.63 \pm 20.02$ \\
& Hypothalamus Non-Obese & $148.78 \pm 22.00$ & $222.91 \pm 28.13$ \\
& Adipose Subcutaneous & $188.45 \pm 39.23$ & $466.13 \pm 51.22$ \\
& Adipose Visceral & $250.31 \pm 29.99$ & $557.25 \pm 68.88$ \\
& Adipocytes Undifferentiated Subcutaneous & $14.15 \pm 2.49$ & $43.03 \pm 6.76$ \\
& Adipocytes Differentiated Subcutaneous & $26.34 \pm 3.04$ & $75.19 \pm 8.95$ \\
& Adipocytes Undifferentiated Visceral & $19.56 \pm 2.28$ & $57.54 \pm 4.72$ \\
& Adipocytes Differentiated Visceral & $36.86 \pm 4.19$ & $94.99 \pm 13.10$ \\
\hline
\end{tabular}

levels relative to undifferentiated precursor cells and adipose tissues from lean humans and subcutaneous depots, respectively.

The putative involvement of the histone methylation state of the donor cells in the release of EMVs harbouring GPI-anchored proteins and RNAs was studied with primary and differentiated rat and human adipocytes of small and large size kept in primary culture in the adherent state. These conditions enabled long-term incubation of the cells with BIX01294 and IPCPA prior to their induction for EMV release. For this, rat large and small adipocytes were prepared by sequential filtration of the floating primary adipocytes or rat adipocytes were differentiated from the sedimenting SVCs. In addition, human adipocytes were differentiated from MSCs derived from resection of abdominal subcutaneous fat depots (see MATERIALS AND METHODS). These four types of adipocytes were cultured on collagen-coated 12-well plates for $90 \mathrm{~h}$ corresponding to the total incubation period that is required for the treatment with the inhibitors, the induction and the EMV releasing assay. The functional integrity of the adipocytes was demonstrated by their sensitivity and responsiveness toward insulin stimulation of lipid synthesis (measured as the incorporation of radiolabeled glucose into cellular acylglycerols) as well as insulin inhibition of isoproterenol-stimulated lipolysis (measured as the release of glycerol into the incubation medium). Short-term incubation with insulin subsequent to a total culturing period of $90 \mathrm{~h}$ led to significant stimulation of lipid synthesis by 3.5 - to up to 19.2-fold above basal and significant inhibition of isoproterenol-stimulated lipolysis by $21 \%$ to $63 \%$ compared to basal at roughly half-maximally effective $(0.3 \mathrm{nM})$ and by 7.5 - to up to 28.7 -fold and $71 \%$ to $95 \%$, respectively, at maximally effective $(100 \mathrm{nM})$ concentrations (Figure 1).

Small primary rat adipocytes were most responsive toward insulin, followed by large primary and differentiated rat adipocytes, and lastly human adipocytes. The responsiveness and sensitivity (i.e. apparent $\mathrm{EC}_{50}$-values) toward insulin of the four distinct types of adipocytes were well within the ranges reported previously for short-term incubation $[42,54]$ and argue for their functional integrity in course of long-term primary culture under the experimental conditions used. Importantly, the presence of BIX01294 and tPCPA alone or in combination at concentrations, that were previously reported to efficiently affect histone methylation in various cell lines $[60,61]$ and were therefore used in the following for long-term incubation of the adipocytes, did not impair significantly half-maximal as well as maximal insulin stimulation of lipid synthesis and inhibition of lipolysis (Figure 1). Since insulin signaling to lipid metabolism in insulin-responsive cells is known to depend strictly on adequate energy charge [64], the four adipocyte types apparently keep their full functional integrity throughout the long-term primary culture in the absence and presence of BIX01294 and/or tPCPA. This was confirmed by measurement of the cell-associated caspase $3 / 7$ activities as markers for apoptosis eventually caused by the in- 


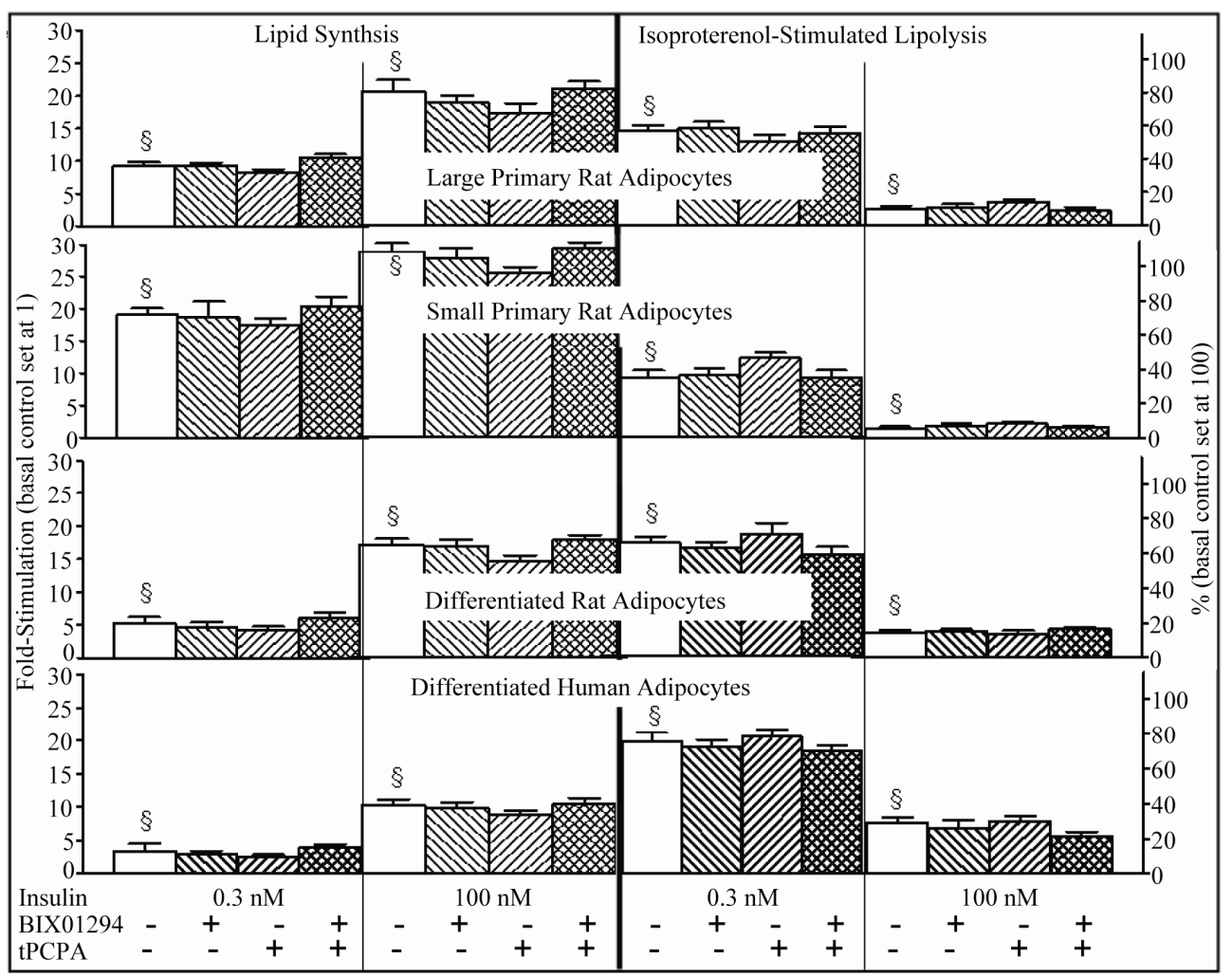

Figure 1. Effects of BIX01294 and tPCPA on the basal and insulin-induced lipid synthesis and isoproterenol-stimulated lipolysis in rat and human adipocytes. Large and small primary rat adipocytes or adipocytes differentiated from rat SVCs and human MSCs (identical numbers per well for each adipocyte type) were incubated $\left(90 \mathrm{~h}, 37^{\circ} \mathrm{C}\right)$ in 12 -well plates in the absence (control; open bars) or presence (treated; hatched bars) of BIX01294 $(30 \mu \mathrm{M})$ or/and tPCPA $(100 \mu \mathrm{M})$ as indicated. The adipocytes were washed and then assayed for lipid synthesis $(1 \mathrm{~h})$ and isoproterenol-stimulated lipolysis $(2 \mathrm{~h})$ in the absence (basal) or presence of human insulin $(0.3$ and $100 \mathrm{nM})$. Fold-stimulation of lipid synthesis above basal (set at 1 for basal control adipocytes of each type) and \% of isoproterenolstimulated lipolysis (set at 100 for basal control adipocytes of each type) are given as means \pm S.D. derived from two to three different adipocyte preparations/differentiations with incubations in duplicate (lipid synthesis) and triplicate (lipolysis), each. Significant differences between the insulin-induced and basal control adipocytes are indicated by ${ }^{\S}$ for each type.

hibitors of histone (de)methylation or/and the inducers of EMV release. Long-term incubation with BIX01294 did not significantly affect caspase $3 / 7$ activities compared to control in each of the four adipocyte types (Figure 2).

In contrast, tPCPA alone or in combination with BIX01294 exerted moderate albeit significant activation of caspase 3/7 compared to control depending on the type of adipocytes. Importantly, palmitate at $1 \mathrm{mM}$ as used for the induction of EMV release was more efficient than IPCPA in eliciting caspase $3 / 7$ activation in each adipocyte type. In contrast, glimepiride at $30 \mu \mathrm{M}$ and $\mathrm{GO}$ at $0.5 \mathrm{U} / \mathrm{ml}$ which provoked either no or only moderate, albeit significant, caspase 3/7 upregulations, respectively, compared to basal depending on the adipocyte type (Figure 2). Thus the efficacies of palmitate, glimepiride and GO in activating caspase 3/7 and inducing EMV release in primary and differentiated rat and human adipocytes are not correlated. The simultaneous challenge of the adipocytes with tPCPA and either palmitate, glimepiride or GO led to less-than-additive to up to additive tPCPA-dependent effects on caspase 3/7 activation compared to basal controls in each of the four induced adipocyte types (Figure 2). In contrast, BIX01294 did not enhance the moderate palmitate- and GO-induced as well as tPCPA-dependent caspase $3 / 7$ activation. Taken together, tPCPA alone or in combination with BIX01294 but not BIX01294 alone, trigger slight caspase 3/7 activations that are further enhanced after induction with palmitate or GO, but not with glimepiride. Small primary rat adipocytes turned out to be less susceptible toward apoptosis than large primary and differentiated rat and human adipocytes (Figure 2). The apparent lack of correlation between caspase 3/7 activation and EMV release upon induction with palmitate, glimepiride and GO in concert with the moderate and differential impact of BIX01294 and TPCPA on the induced caspase 3/7 sug- 


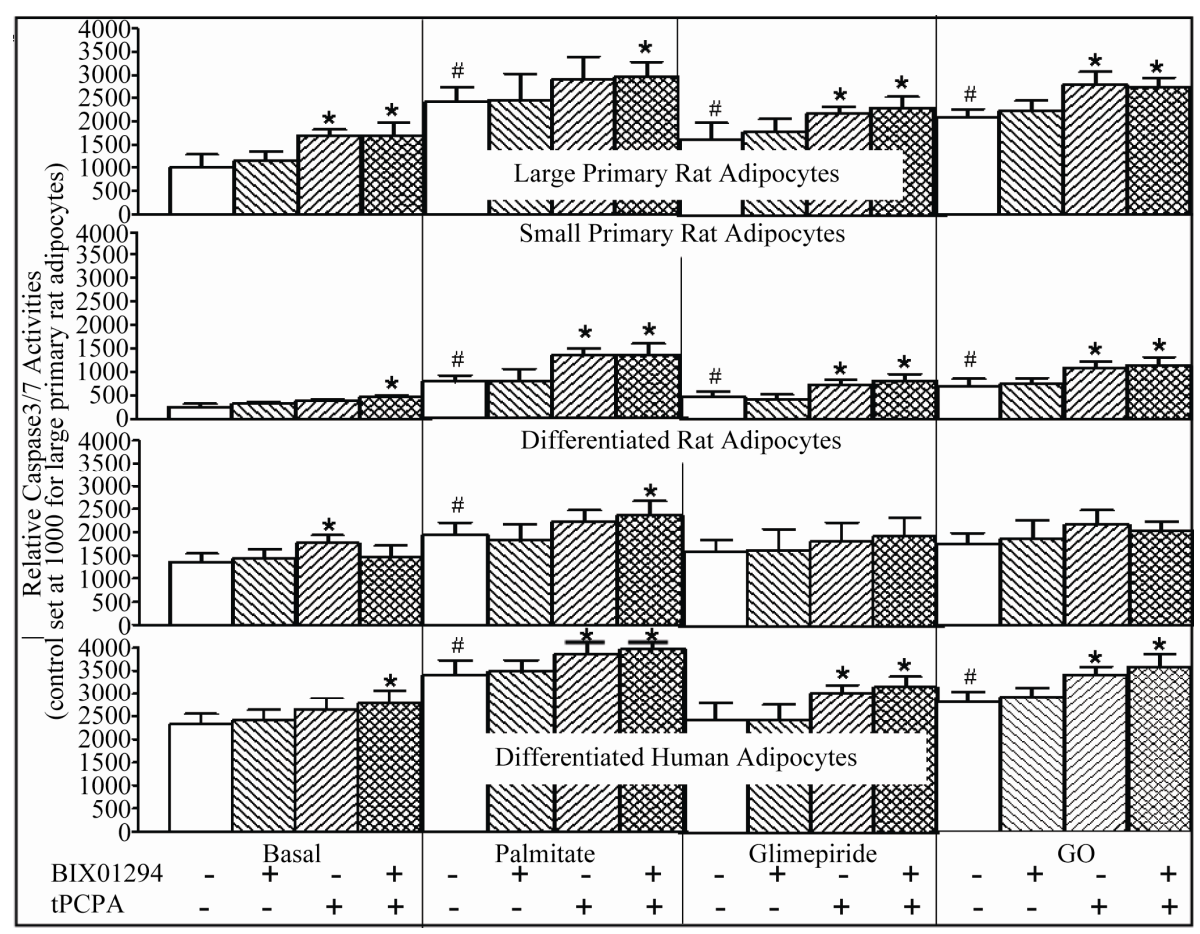

Figure 2. Effects of BIX01294 and tPCPA on apoptosis in basal and induced rat and human adipocytes. Large and small primary rat adipocytes or adipocytes differentiated from rat SVCs and human MSCs (identical numbers per well for each adipocyte type) were incubated ( $70 \mathrm{~h}$, $37^{\circ} \mathrm{C}$ ) in 12-well plates in the absence (control; open bars) or presence (treated; hatched bars) of BIX01294 $(30 \mu \mathrm{M})$ or/and tPCPA $(100 \mu \mathrm{M})$ as indicated. Thereafter, the incubation was continued in the absence (basal) or presence (induced) of palmitate $(1 \mathrm{mM})$, glimepiride ( 30 $\mu \mathrm{M})$ or $\mathrm{GO}(0.5 \mathrm{U} / \mathrm{ml})$ for $20 \mathrm{~h}$. Adipocyte-associated caspase $3 / 7$ activities were measured and given as means \pm S.D. derived from three different adipocyte preparations/differentiations with incubations in quadruplicate, each. Significant differences between the induced and basal control adipocytes (set at 1000 for large primary rat adipocytes) are indicated by ${ }^{\#}$ and between the treated and control (basal or induced) adipocytes by ${ }^{*}$ for each type.

gests that under the experimental conditions used the induced release of EMVs from the adipocytes is not the consequence of increased apoptosis.

Next the impact of inhibition of G9a and LSD1 on the release of EMVs harbouring specific GPI-anchored proteins (Figure 3), mRNAs (Figure 4) and miRNAs (Figure 5) was studied with each of the four types of adipocytes. For this, the adipocytes were incubated for long term in primary culture with BIX01294 or tPCPA (prior to metabolic pulse labeling with $m y o-\left[{ }^{14} \mathrm{C}\right]$ inositol; for Figure 3 only) and then induced with palmitate, glimepiride or GO or not (basal)(under chase conditions; for Figure 3 only). CD73- and Gce1-harbouring EMVs were prepared from the incubation media by successive filtration, centrifugation and affinity purification on either AMP- or cAMP-Sepharose, respectively (Figure 3) or a mixture thereof (Figures 4 and 5). For the detection of CD73 (Figure 3(a)) or Gcel (Figure 3(b)) proteins, total polypeptides recovered with the purified and collected EMVs were separated by SDS-PAGE and visualized by phosphorimaging. For the analysis of mRNAs specific for FSP27 (Figure 4(a)) or GPAT3 (Figure 4(b)) and of miRNAs, miR-16 (Figure 5) and miR-222 (Figure 6), the qRT-PCR products amplified with specific primer sets from the total RNA of the purified and collected EMVs were separated by agarose gel electrophoresis and visualized under UV light.

For each of the four adipocyte types in the basal state the images revealed $\left[{ }^{14} \mathrm{C}\right]$ inositol-labeled bands and PCR products that corresponded to the size of the CD73 (Figure 3(a)) and Gcel (Figure 3(b)) proteins, FSP27 (Figure 4(a)) and GPAT3 (Figure 4(b)) mRNAs and miR-16 (Figure 5) and miR-222 (Figure 6) miRNAs. The identity of the GPI-anchored proteins and transcripts have previously been proven on the basis of their radiolabeling and binding to (c)AMP-Sepharose as well as sequencing of the PCR products and in vitro translation into the corresponding FSP27 and GPAT3 proteins [24]. The amounts of EMVs harbouring CD73/Gcel proteins (Figure 3), FSP27-/GPAT3-specific mRNAs (Figure 4) and miR-16/miR-222 (Figures 5 and 6, Control panel) were significantly elevated compared to basal upon in- 


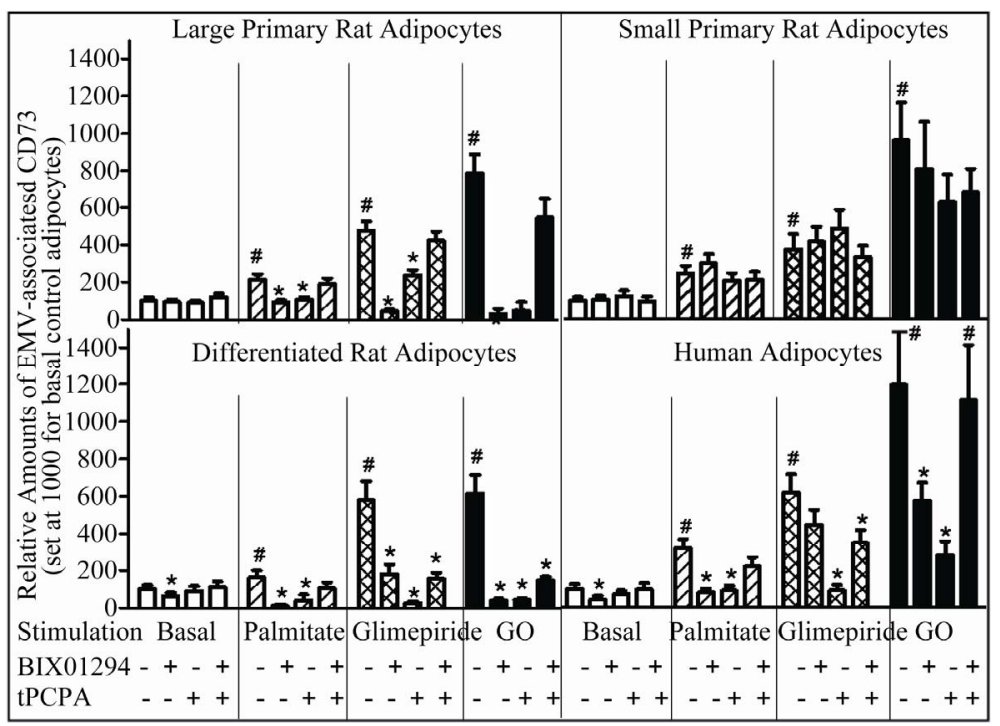

(a)

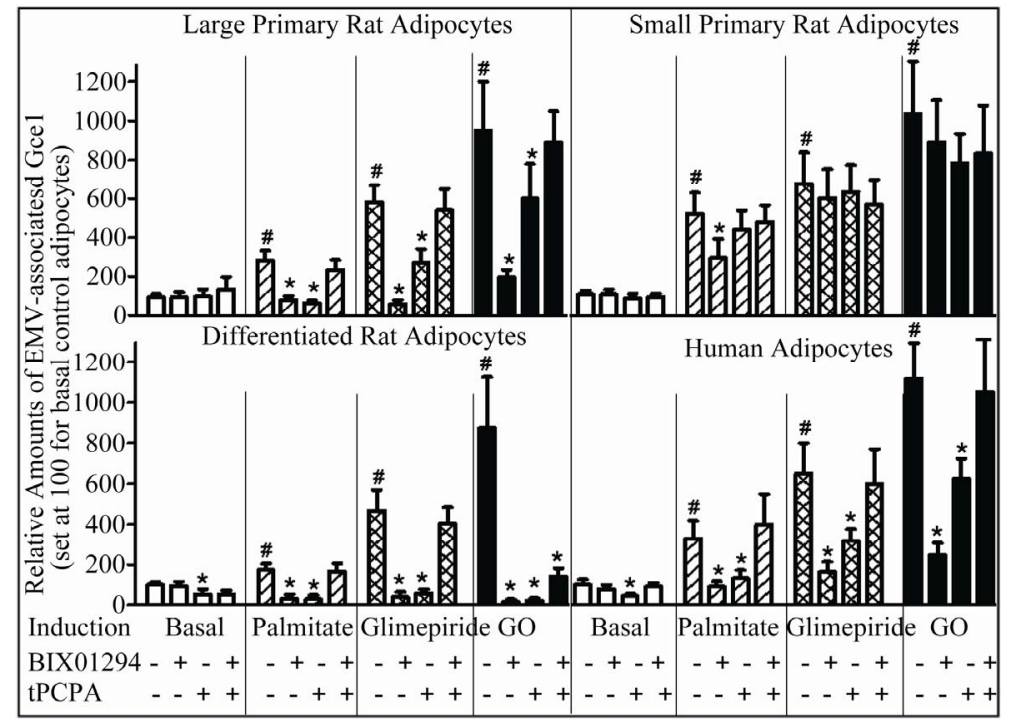

(b)

Figure 3. Effects of BIX01294 and tPCPA on the basal and induced release of CD73 (a) and Gce1 (b) proteins into EMVs from rat and human adipocytes. Large and small primary rat adipocytes or adipocytes differentiated from rat SVCs and human MSCs (identical numbers per well for each adipocyte type) were incubated $\left(70 \mathrm{~h}, 37^{\circ} \mathrm{C}\right)$ in 12-well plates in the absence (control) or presence (treated) of BIX01294 $(30 \mu \mathrm{M})$ or/and tPCPA $(100 \mu \mathrm{M})$ as indicated. Thereafter, the adipocytes were washed and incubated $\left(2 \mathrm{~h}, 37^{\circ} \mathrm{C}\right)$ in labeling medium containing or lacking BIX01294 or/and tPCPA as above and then metabolically labeled ( $2 \mathrm{~h}$, $37^{\circ} \mathrm{C}$ ) with $m y o-\left[{ }^{14} \mathrm{C}\right]$ inositol. Following washing with labeling medium lacking $m y o-\left[{ }^{14} \mathrm{C}\right]-$ inositol and supplemented with myo-inositol $(100 \mathrm{mM})$, the adipocytes were incubated $(16 \mathrm{~h}$, $37^{\circ} \mathrm{C}$ ) in the absence (basal, open bars) or presence (induction) of palmitate $(1 \mathrm{mM}$, hatched bars), glimepiride ( $30 \mu \mathrm{M}$, cross-hatched bars) or GO $(0.5 \mathrm{U} / \mathrm{ml}$, filled bars) in the above medium containing or lacking BIX01294 or/and tPCPA as above. Total EMVs were prepared from the incubation medium by sequential filtration, centrifugation and affinity-purification using AMP (a) or cAMP (b) Sepharose beads. After dissociation from the beads and centrifugation, the collected EMVs were suspended in two-fold Laemmli sample buffer and analyzed by SDS-PAGE and phosphorimaging. Means \pm S.D. (4 different preparations of each adipocyte type with incubations in duplicate, each) are given. Significant differences between the induced and basal control adipocytes (set at 100 for each type) are indicated by \# and between the treated and control (basal or induced) adipocytes by ${ }^{*}$ for each type. 


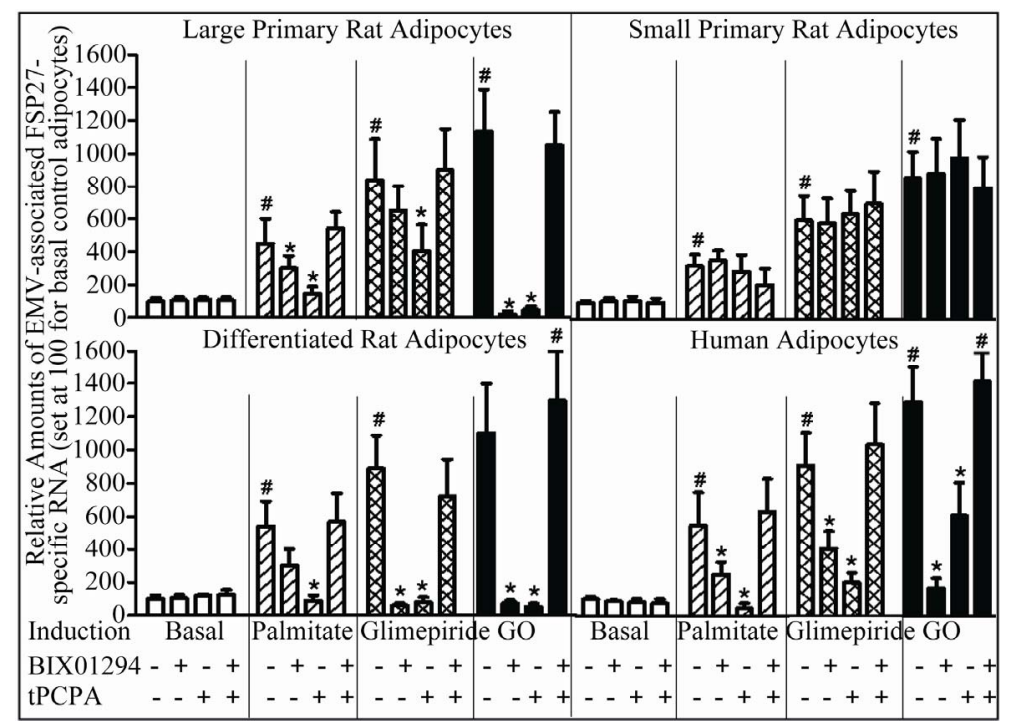

(a)

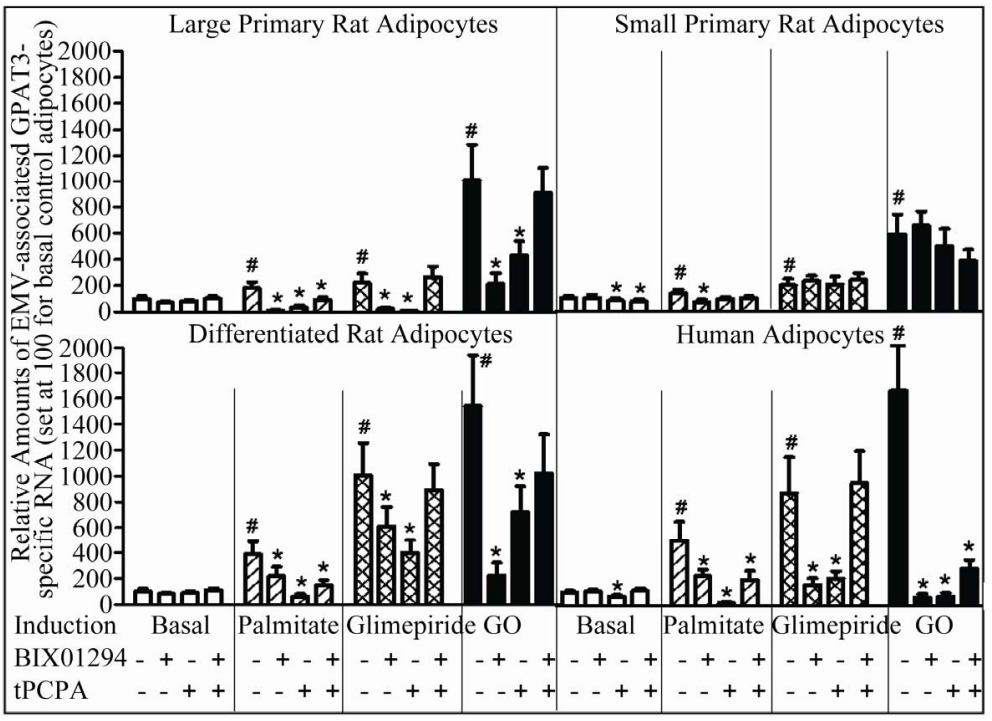

(b)

Figure 4. Effects of BIX01294 and tPCPA on the basal and induced release of FSP27 (a) and GPAT3 (b) specific mRNAs into EMVs from rat and human adipocytes. Large and small primary rat adipocytes or adipocytes differentiated from rat SVCs and human MSCs (identical numbers per well for each adipocyte type) were incubated $\left(70 \mathrm{~h}, 37^{\circ} \mathrm{C}\right)$ in 12 -well plates in the absence (control) or presence (treated) of BIX01294 $(30 \mu \mathrm{M})$ or/and tPCPA $(100 \mu \mathrm{M})$ as indicated. Thereafter, the adipocytes were washed and then incubated $\left(20 \mathrm{~h}, 37^{\circ} \mathrm{C}\right)$ in the absence (basal, open bars) or presence (induction) of palmitate ( $1 \mathrm{mM}$, hatched bars), glimepiride (30 $\mu \mathrm{M}$, cross-hatched bars) or GO $(0.5 \mathrm{U} / \mathrm{ml}$, filled bars) in medium containing or lacking BIX01294 or/and tPCPA as above. Total EMVs were prepared from the incubation medium by sequential filtration and centrifugation and subsequently affinity-purified using mixtures of AMP- and cAMP-Sepharose beads. After dissociation from the beads and centrifugation, the collected EMVs were used for the isolation of total RNA. Portions of the RNA were used for qRT-PCR with primer sets specific for FSP27 (a) or GPAT3 (b). Means \pm S.D. derived from three different preparations of each adipocyte type with incubations in triplicate, each, are given. Significant differences between the induced and basal control adipocytes (set at 100 for each type) are indicated by ${ }^{\#}$ and between the treated and control (basal or induced) adipocytes by ${ }^{*}$ for each type. 


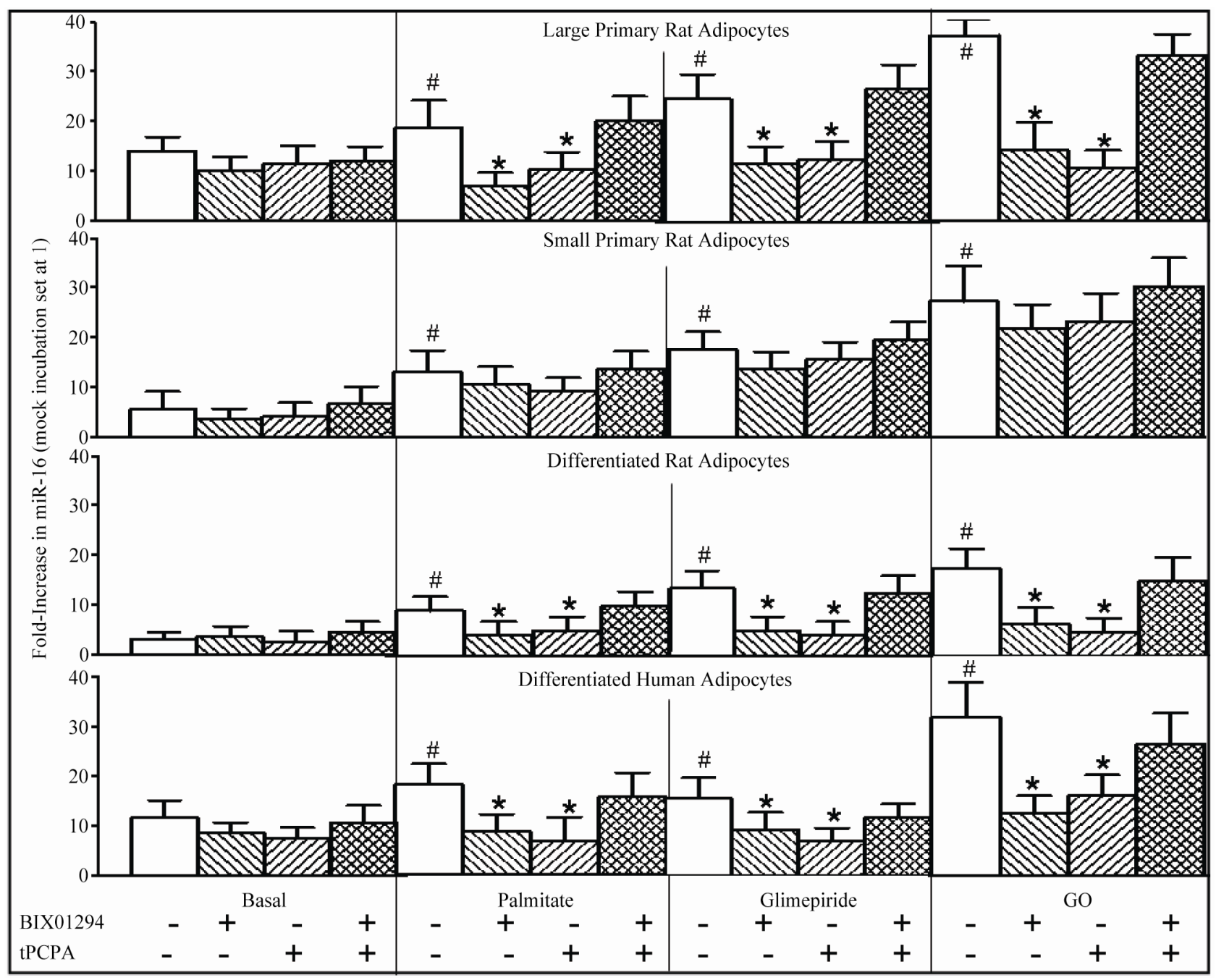

Figure 5. Effects of BIX01294 and tPCPA on the basal and induced release of the miR-16 miRNA into EMVs from rat and human adipocytes. Large and small primary rat adipocytes or adipocytes differentiated from rat SVCs and human MSCs (identical numbers per well for each adipocyte type) were incubated $\left(70 \mathrm{~h}, 37^{\circ} \mathrm{C}\right)$ in 12 -well plates in the absence (control, open bars) or presence (treated; hatched bars) of BIX01294 $(30 \mu \mathrm{M})$ or/and IPCPA $(100 \mu \mathrm{M})$ as indicated. Thereafter, the adipocytes were washed and then incubated $\left(37^{\circ} \mathrm{C}\right)$ in the absence (basal) or presence (induced) of palmitate $(1 \mathrm{mM})$, glimepiride $(30 \mu \mathrm{M})$ or $\mathrm{GO}(0.5 \mathrm{U} / \mathrm{ml})$ in medium containing or lacking BIX01294 or/and tPCPA as above for $20 \mathrm{~h}$ or $0 \mathrm{~h}$ (mock incubation). Total EMVs were prepared from the incubation medium by sequential filtration and centrifugation and subsequently affinity-purified using mixtures of AMP- and cAMPSepharose beads. After dissociation from the beads and centrifugation, the collected EMVs were used for the isolation of total RNA. Portions of the RNA were used for qRT-PCR with primer sets specific for miR-16. The fold-increases of miR-16 are standardized to that of U6snRNA (set at 1 for the mock incubation) and given as means \pm S.D. derived from two to four different adipocyte preparations/differentiations with incubations in quadruplicate, each. Significant differences between the induced and basal control adipocytes are indicated by ${ }^{\#}$ for each type and between the treated and control (basal or induced) adipocytes by ${ }^{*}$ for each type.

duction with palmitate, glimepiride or GO in that order of increasing potency and with fold-stimulations above basal comparable between the four types of adipocytes (palmitate/glimepiride/GO: CD73, 1.6 - 2.4/3.7 - 6.2/6.2 - 11.9; Gce1, 1.7 - 4.9/4.7 - 6.5/8.8 - 13.0; FSP27, 3.2 5.6/6.0 - 9.2/8.7 - 14.8; GPAT3, 1.4 - 5.0/2.0 - 9.6/5.9 19.1; miR-16, 1.7 - 2.3/1.4 - 3.1/2.8 - 4.7; miR-222, 1.6 2.8 for GO). This was the first demonstration of the (basal and induced) release of EMVs from human adipocytes that may hint to its relevance in health and dis- ease.

Long-term incubation with BIX01294 or/and tPCPA did not affect or reduced moderately, albeit significantly (by $27 \%$ to $48 \%$ ), the basal release of EMVs harbouring the CD73/Gce1 proteins (Figure 3), FSP27-/GPAT3specific mRNAs (Figure 4) and miR-16/miR-222 (Figure 5/data not shown), depending on the adipocyte type and incubation condition. However, BIX01294 or tPCPA drastically impaired the palmitate-, glimepiride- and GOinduced release of these EMVs under each incubation 


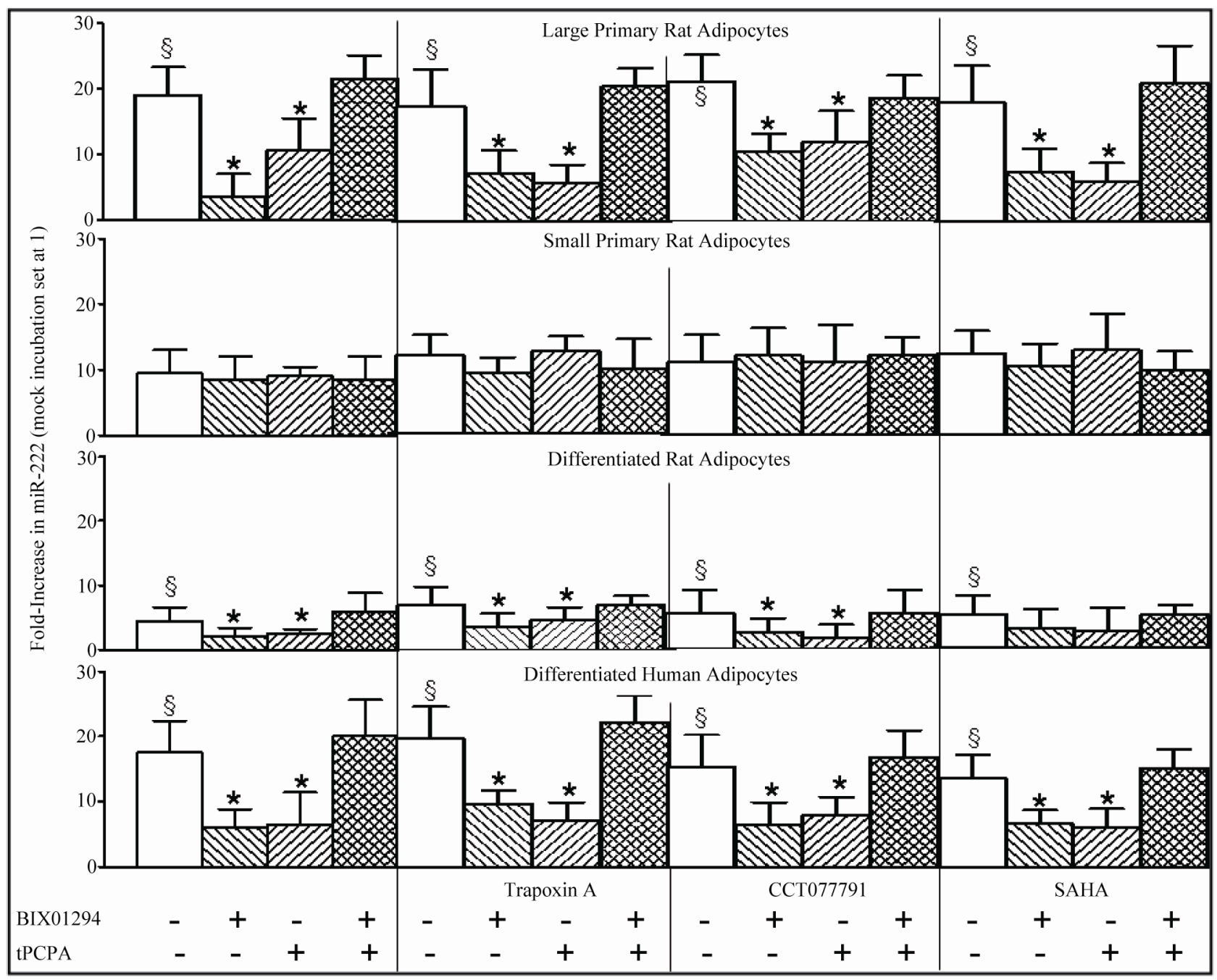

Figure 6. Effects of histone (de)methylation and (de)acetylation on the GO-induced release of miR-222 into EMVs from rat and human adipocytes. Large and small primary rat adipocytes or adipocytes differentiated from rat SVCs and human MSCs (identical numbers per well for each adipocyte type) were incubated $\left(70 \mathrm{~h}, 37^{\circ} \mathrm{C}\right)$ in 12 -well plates in the absence (control; open bars) or presence (treated; hatched bars) of BIX01294 $(30 \mu \mathrm{M})$, tPCPA $(100 \mu \mathrm{M})$, trapoxin A $(100 \mu \mathrm{M})$, CCT077791 $(30 \mu \mathrm{M})$ and SAHA $(50 \mu \mathrm{M})$ alone or in combination as indicated. Thereafter, the adipocytes were washed and then incubated $\left(37^{\circ} \mathrm{C}\right)$ in the absence (basal) or presence of $\mathrm{GO}(0.5 \mathrm{U} / \mathrm{ml})$ in medium containing or lacking the inhibitors as above for $20 \mathrm{~h}$ or $0 \mathrm{~h}$ (mock incubation). Total EMVs were prepared from the incubation medium by sequential filtration and centrifugation and subsequently affinity-purified using mixtures of AMP- and cAMP-Sepharose beads. After dissociation from the beads and centrifugation, the collected EMVs were used for the isolation of total RNA. Portions of the RNA were used for qRT-PCR for miR-222. The fold-increases of miR-222 are standardized to that of U6 small nuclear RNA, RNU6B (set at 1 for the mock incubation) and given as means \pm S.D. derived from two to three different adipocyte preparations/differentiations with incubations in triplicate, each. Significant differences between the GOinduced and basal (data not shown) control adipocytes are indicated by ${ }^{\S}$ for each type and between the trapoxin A-, CCT077791- or SAHA-treated and control GO-induced adipocytes by ${ }^{*}$ for each type.

condition in large primary (by $40 \%$ to $100 \%$ ) and differentiated rat adipocytes (by $41 \%$ to $100 \%$ ) as well as human adipocytes (by $34 \%$ to $100 \%$ ), but not in small primary rat adipocytes. Strikingly, in the course of simultaneous presence of BIX01294 and tPCPA the amounts of EMVs harbouring CD73/Gce1 proteins (Figure 3), FSP27-/GPAT3-specific mRNAs (Figure 4) and miR-16/ miR-222 (Figure 5/data not shown) released from basal and, in particular, palmitate-, glimepiride- and GO-in- duced (for miR-222 shown only, Figure 6, Control panel) large primary and differentiated rat and human adipocytes were less pronouncedly lowered compared to the separate treatments and under most conditions did not differ significantly from the corresponding control incubations. Taken together, inhibition of either G9a or LSD1, but not of both together, in the long-term blocks the induced release of EMVs harbouring specific GPIanchored proteins, mRNAs and miRNAs from large (but 
not small) primary rat adipocytes as well as differentiated rat und human adipocytes.

To characterize the specificity of the apparent inhibition of the EMV release by interference with histone methylation, the putative impact of histone acetylation was studied by long-term incubation of the four different types of adipocytes with the anti-tumor cyclic tetrapeptide, trapoxin A, and the suberoylanilide hydroxamic acid derivative, SAHA, which both inhibit the 11 classical histone deacetylases with similar potency [57], as well as the isothiazolone derivative, CCT077791, which blocks histone acetyltransferases with low micromolar potency without great specificity [65].

Determination of the amount of miR-222 in CD73/ Gce1-harbouring EMVs released into the incubation medium following challenge of the adipocytes with GO did not reveal any significant alteration provoked by trapoxin A, SAHA or CCT077791 at concentrations known to be effective in various cellular systems [66] compared to the control incubation in each of the four types of adipocytes (Figure 6, open bars). To test for the possibility of interactions between histone methylation and acetylation in the control of EMV release as has been described previously for DNA and histone methylation during tumor progression [67], trapoxin A, SAHA and CCT077791 were incubated together with BIX01294 or/and tPCPA. The three inhibitors of histone (de)acetylation did not exert significant effects on the abrogation of the GOinduced release of miR-222 into CD73/Gce1-harbouring EMVs in large primary and differentiated rat and human adipocytes (Figure 6, hatched bars) and also did not counteract the EMV release that was fully restored by the combination of BIX01294 and tPCPA (Figure 6, crosshatched bars). The ineffectiveness of trapoxin A, SAHA and CCT077791 was also demonstrated for the palmitate- and glimepiride-induced release of affinity-purified EMVs harbouring the GPI-anchored protein CD73 and FSP27-specific mRNA (Müller, G., Wied. S., and Schneider, M., data not shown). Assuming successful interference with histone (de)acetylases in the four types of adipocytes by the inhibitors under the conditions used here, which seems to be likely on the basis of previously reported findings [66], the release of EMVs harbouring specific GPI-anchored proteins and RNAs from rat and human adipocytes is apparently not controlled by histone acetylation.

Recently, the release of EMVs from cultured mouse [3, 4] and primary rat adipocytes [5,6] has been demonstrated to be upregulated by insulin, albeit in comparison to glimepiride and $\mathrm{H}_{2} \mathrm{O}_{2}$ only to a moderate degree. Consequently, the involvement of the histone methylation state in the insulin-induced release of EMVs harbouring specific GPI-anchored proteins and RNAs from the four types of adipocytes was studied under the same experimental conditions that had revealed a role of G9a and LSD1 in the control of EMV release in response to palmitate, glimepiride and GO (see Figures 3-6). Insulin stimulated the release of EMVs harbouring the GPI-anchored proteins, Gce1 and CD73, and FSP27- and GPAT3specific mRNAs into the incubation medium of large primary rat adipocytes by 1.8/2.6/1.6/3.1-fold (Gce1/ CD73/FSP27/GPAT3), small primary rat adipocytes by 2.0/2.3/2.0/1.6-fold, differentiated rat adipocytes by $2.8 /$ 3.0/1.8/2.3-fold and differentiated human adipocytes by 1.7/2.0/6.0/4.9-fold (Figure 7). Thus insulin manages to release EMVs from both rat and human adipocytes with a potency comparable to that of palmitate, but considerably lower than that of glimepiride and GO. Remarkably, in contrast to the cell size-dependent inductions provoked by palmitate, glimepiride and GO, large and small primary rat adipocytes did not differ significantly in the efficacy of the insulin-induced EMV release. Furthermore, in contrast to the palmitate, glimepiride and GO induction, long-term incubation with BIX01294 as well as tPCPA (under the majority of the conditions) prior to incubation with insulin did not significantly impair the release of Gce1/CD73 proteins and FSP27-/GPAT3specific mRNAs into EMVs of primary and differentiated rat and human adipocytes (Figure 7). Taken together, these data do not argue for control of the insulininduced release of EMVs harbouring specific GPI-anchored proteins and RNAs by the histone methylation state, at least not with the responsiveness as observed for the palmitate-, glimepiride- and GO-induced one.

The mechanism of the release of Gce1 and CD73 from rat adipocytes into EMVs has previously been found to encompass several distinct steps, including 1) their initial translocation from the outer leaflet of the plasma membrane to the surface of cytoplasmic LDs with the GPI anchors undergoing insertion into the LD phospholipid monolayer and 2) their subsequent transfer from the LDs onto the surface of EMVs with the GPI anchors being incorporated into the outer leaflet of the EMV phospholipid bilayer $[2,7,24,68]$. To study the putative involvement of histone (de)methylation in the individual steps of EMV release, primary rat adipocytes were incubated for long-term in primary culture with BIX01294 or/and tPCPA prior to metabolic pulse labeling with $m y o-\left[{ }^{14} \mathrm{C}\right]-$ inositol and then induced with GO or kept in the basal state under chase conditions. Metabolically labeled, extracted and affinity-purified CD73 and Gce1 proteins were then recovered with plasma membranes and LDs prepared from the adipocytes and detected by SDS-PAGE and phosphorimaging (Figure 8).

As expected, incubation of both large and small rat adipocytes with GO led to significant losses from the plasma membranes of CD73 (by $42 \%$ and $49 \%$, respectively) and Gce1 (by $24 \%$ and $12 \%$, respectively) and, in 


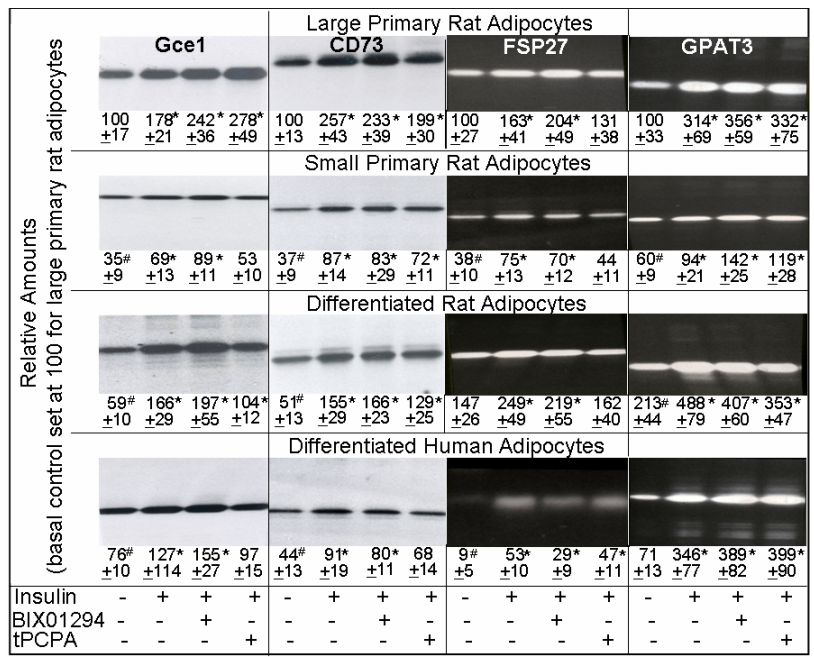

Figure 7. Effects of BIX01294 and tPCPA on the insulin-induced release of Gce1/CD73 proteins and FSP27-/GPAT3-specific mRNAs into EMVs from rat and human adipocytes. Large and small primary rat adipocytes or adipocytes differentiated from rat SVCs and human MSCs (identical numbers per well for each adipocyte type) were incubated $\left(70 \mathrm{~h}, 37^{\circ} \mathrm{C}\right)$ in 12 -well plates in the absence (control) or presence (treated) of BIX01294 $(30 \mu \mathrm{M})$ or/and tPCPA $(100 \mu \mathrm{M})$ as indicated. Thereafter, the adipocytes were washed and incubated $\left(2 \mathrm{~h}, 37^{\circ} \mathrm{C}\right)$ in labeling medium containing or lacking BIX01294 or/and tPCPA as above and then metabolically labeled $\left(2 \mathrm{~h}, 37^{\circ} \mathrm{C}\right)$ with $m y o-\left[{ }^{14} \mathrm{C}\right]$ inositol as described in Materials and Methods. Following washing with labeling medium lacking myo- $\left[{ }^{14} \mathrm{C}\right]$ inositol and supplemented with myo-inositol $(100 \mathrm{mM})$, the adipocytes were incubated $\left(16 \mathrm{~h}, 37^{\circ} \mathrm{C}\right)$ in the absence (basal) or presence of insulin $(10 \mathrm{nM})$ in the above medium containing or lacking BIX01294 or/and tPCPA as above. Total EMVs were prepared from the incubation medium by sequential filtration and centrifugation and subsequently affinity-purified using mixtures of AMP- and cAMP-Sepharose beads. After dissociation from the beads and centrifugation, portions of the collected EMVs were suspended in two-fold Laemmli sample buffer and analyzed by SDS-PAGE and phosphorimaging. Representative images for CD73 and Gcel are shown. Other portions of the collected EMVs were used for the isolation of total RNA. Portions of the RNA were used for qRT-PCR with primer sets specific for FSP27 or GPAT3. Representative images from the agarose gel electrophoresis of the FSP27 and GPAT3 PCR products are shown. Means \pm S.D. derived from two different adipocyte preparations/differentiations with incubations in triplicate, each, are given. Significant differences between the insulin-induced (control or treated) and basal (control) adipocytes are indicated by ${ }^{*}$ for each type and between the basal control large primary rat adipocytes (set at 100) and the other types of adipocytes by ${ }^{\#}$.

parallel, to significant gains at the LDs of CD73 (by 3.2 and 7.2-fold, respectively) and Gcel (by 1.9- and 3.4-fold, respectively) compared to basal (Figure 8). This reflects the known GO-induced translocation of CD73 and Gce1 from the plasma membranes to the LDs, that is more effective in small compared to large adipocytes [30]. BIX01294 and tPCPA alone or in combination did not

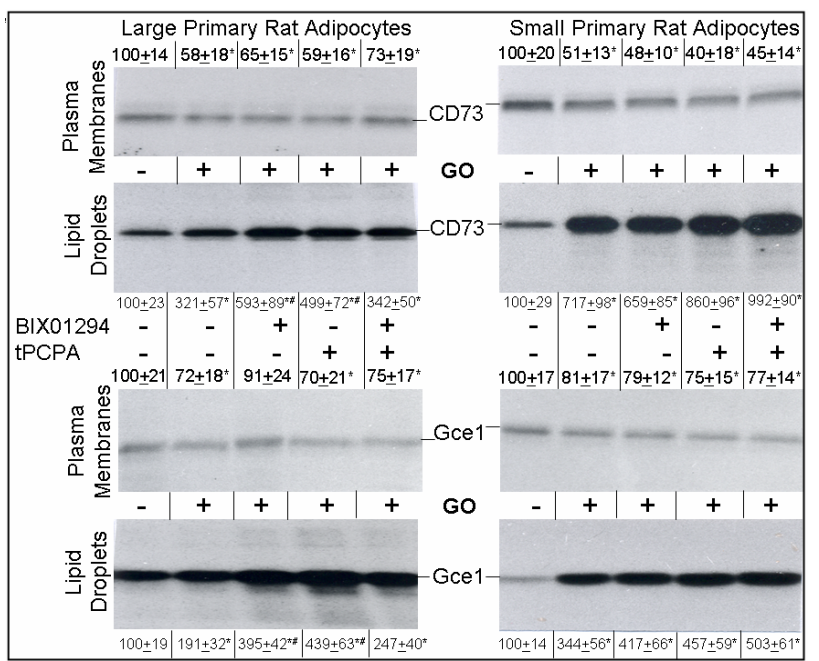

Figure 8. Effects of BIX01294 and tPCPA on the basal and GO-induced translocation of CD73 protein from plasma membranes to LDs in large and small rat adipocytes. Large and small primary rat adipocytes (identical numbers per well for each adipocyte type) were incubated $\left(70 \mathrm{~h}, 37^{\circ} \mathrm{C}\right)$ in 12 -well plates in the absence (control) or presence (treated) of BIX01294 $(30 \mu \mathrm{M})$ or/and tPCPA $(100 \mu \mathrm{M})$ as indicated. Thereafter, the adipocytes were washed and incubated $\left(2 \mathrm{~h}, 37^{\circ} \mathrm{C}\right)$ in labeling medium containing or lacking BIX01294 or/and tPCPA as above and then metabolically labeled $\left(15 \mathrm{~min}, 37^{\circ} \mathrm{C}\right)$ with $m y o-$ $\left[{ }^{14} \mathrm{C}\right]$ inositol as described in Materials and Methods. Following washing with labeling medium lacking $m y o-\left[{ }^{14} \mathrm{C}\right]$ inositol and supplemented with myo-inositol $(100 \mathrm{mM})$, the adipocytes were incubated $\left(1 \mathrm{~h}, 37^{\circ} \mathrm{C}\right)$ in the absence (basal) or presence (induced) of $\mathrm{GO}(0.5 \mathrm{U} / \mathrm{ml})$ in the above medium containing or lacking BIX01294 or/and tPCPA as above. Plasma membranes and LDs were prepared from the washed adipocytes. Total proteins were extracted under non-denaturing conditions and then used for affinity-purification on AMP-Sepharose (for CD73) or cAMP-Sepharose (for Gce1) beads. After incubation $\left(16 \mathrm{~h}, 4^{\circ} \mathrm{C}\right)$ of the beads with $1 \mathrm{mM}$ (c)AMP and centrifugation the supernatants were diluted in the same volume of two-fold Laemmli sample buffer and analyzed by SDS-PAGE and phosphorimaging. Representative images are shown. Means \pm S.D. derived from three different adipocyte preparations/incubations with preparations in duplicate, each, are given. Significant differences between the GO-induced and basal control (large or small) adipocytes (set at 100 for plasma membranes and LDs, each) are indicated by ${ }^{*}$ and between the GO-induced treated and control (large or small) adipocytes by ${ }^{\#}$.

significantly counteract the reduction in CD73 and Gce1 proteins at the plasma membranes in response to GO in both large and small adipocytes (Figure 8). Importantly, in large, but not in small, adipocytes the amounts of CD73 and Gcel accumulating at the LDs during the chase period under concomitant exposure to GO were significantly higher following long-term incubation with either BIX01294 (by 185\% and 207\%, respectively) or tPCPA (by 155\% and 230\%, respectively) compared to the induced untreated controls. In contrast, the combination of the two inhibitors did not alter significantly the 
GO-induced LD association of CD73 and Gce1 in both large and small adipocytes (Figure 8). Effects of BIX01294 or/and tPCPA comparable to those on GOinduced large primary rat adipocytes were also observed with GO- and palmitate-induced differentiated human adipocytes, albeit the latter often failed to reach significance (Müller, G., Wied, S., Schneider, M., data not shown). The apparent upregulation of CD73 and Gce1 protein expression at the LDs of induced large, but not small, adipocytes by BIX01294 and tPCPA without accompanying downregulation at the plasma membranes as revealed by the pulse-chase experiments suggests that G9a and LSD1 are not engaged in the control of translocation of the GPI-anchored proteins from the plasma membranes to the LDs. Rather, the histone methylation state seems to be critical for the subsequent transfer to and insertion into EMVs of the GPI-anchored proteins with its modulation (in course of G9a or LSD1 inhibition) leading to blockade of the release of CD73/Gce1-harbouring EMVs and, in parallel, to accumulation of CD73 and Gce1 at the LDs. The observations that BIX01294 or tPCPA alone and the combination of the inhibitors block and fail to block, respectively, the transfer from the LDs (Figure 8) as well as the release into EMVs (Figure 3) of the GPI-anchored proteins further corroborate the mechanistic coupling of these two steps and their regulation by histone methylation.

The apparent upregulation of CD73 and Gce1 protein expression at the LDs (Figure 8) in combination with downregulation of the induced release of EMVs harbouring these GPI-anchored proteins (Figure 3) and FSP27-/GPAT3-specific mRNAs (Figure 4) in large primary and differentiated rat and human adipocytes as a consequence of G9a and LSD1 inhibition predicts further stimulation of lipid synthesis and inhibition of lipolysis under these conditions. To test for this, the four types of adipocytes were incubated for long-term in primary culture with BIX01294 or/and IPCPA prior to the induction with GO. Subsequent measurement of the incorporation of radiolabeled glucose into acylglycerols and release of glycerol into the incubation medium upon isoproterenol challenge confirmed significant GO-induced upregulation of lipid synthesis (by 6.4- to 19.1-fold compared to basal) and downregulation of isoproterenol-stimulated lipolysis (to $43.7 \%$ to $8.8 \%$ compared to basal) with the effects being most pronounced with small primary rat adipocytes (Figure 9). In the presence of either BIX01294 or tPCPA during long-term primary culture, but not of both inhibitors together GO-induced lipid synthesis stimulation and lipolysis inhibition were significantly enhanced by $19 \%$ to $48 \%$ and $42 \%$ to $65 \%$, respectively, in large primary and differentiated rat and human adipocytes. Strikingly, in small primary rat adipocytes BIX01294 or/and tPCPA had no effect (Figure
9).

In conclusion, the abrogation of the induced release of EMVs harbouring specific RNAs and GPI-anchored proteins that is provoked in large primary and differentiated rat and human adipocytes, but not in small primary rat adipocytes, by modulation of the histone methylation state in course of G9a or LSD1 blockade fosters the induced, but not basal, lipid synthesis and lipolysis inhibition. This may be the consequence of accumulation of GPAT3-/FSP27-specific mRNAs and miR-16/miR-222 in the cytoplasm as well as GPI-anchored proteins CD73/ Gce1 at the LD surface of the EMV donor adipocytes.

\section{DISCUSSION}

The experimental evidence for a causal linkage between the histone methylation state and adipocyte differentiation and growth, collectively termed adipogenesis is steadily increasing. So far, emphasis has been put on the promoters of key adipogenic genes for transcription factors, such as pparg and cebpa. Their expression has to be induced more than 200-fold for the induction of adipocyte differentiation and is correlated to significant increases in H3K4 methylation at their promoters [69]. In accordance, PTIP, a protein that associates with the H3K4 histone methyltransferases, MLL3 and MLL4, and thereby regulates histone methylation, is essential for adipogenesis [69]. Deletion of PTIP impairs the methylation of $\mathrm{H} 3 \mathrm{~K} 4$ and the loading of RNA polymerase II on the pparg and cebpa promoters resulting in downregulation of $\operatorname{PPAR} \gamma$ and $\mathrm{C} / \mathrm{EBP} \alpha$ expression. Furthermore, knockdown of LSD1 has been shown to lead to a marked impairment in the differentiation of 3T3-L1 preadipocytes in parallel with increased $\mathrm{H} 3 \mathrm{~K}$ 9me2 levels at the cebpa promoter [70]. This argues for a role of LSD1 in opposing the action of $\mathrm{H} 3 \mathrm{~K} 9$ methyltransferase at the chromatin of the cebpa promoter. In agreement, knockdown of the H3K9 methyltransferase, SETDB1, produces the opposite phenotype, i.e. promotion of the differentiation of 3T3-L1 preadipocytes, in course of decreasing H3K9me2 levels [70].

An additional layer of complexity to the epigenetic control of adipogenesis, with emphasis on the late maturation stage of lipid storage and cell size increase rather than on the early differentiation from precursor cells, is provided by the presented findings. These can be reconciled into the following hypothetical model for a role of the $\mathrm{H} 3 \mathrm{~K} 9$ and $\mathrm{H} 3 \mathrm{~K} 4$ methylation states in the regulated release of EMVs harbouring specific GPI-anchored proteins and RNAs from adipocytes (Figure 10). Importantly, the findings that 1) BIX01294 and TPCPA alone or in combination as well as palmitate and GO cause slight increases in caspase 3/7 activity (Figure 2), and 2) the inhibitors alone, but not in combination, downregu 


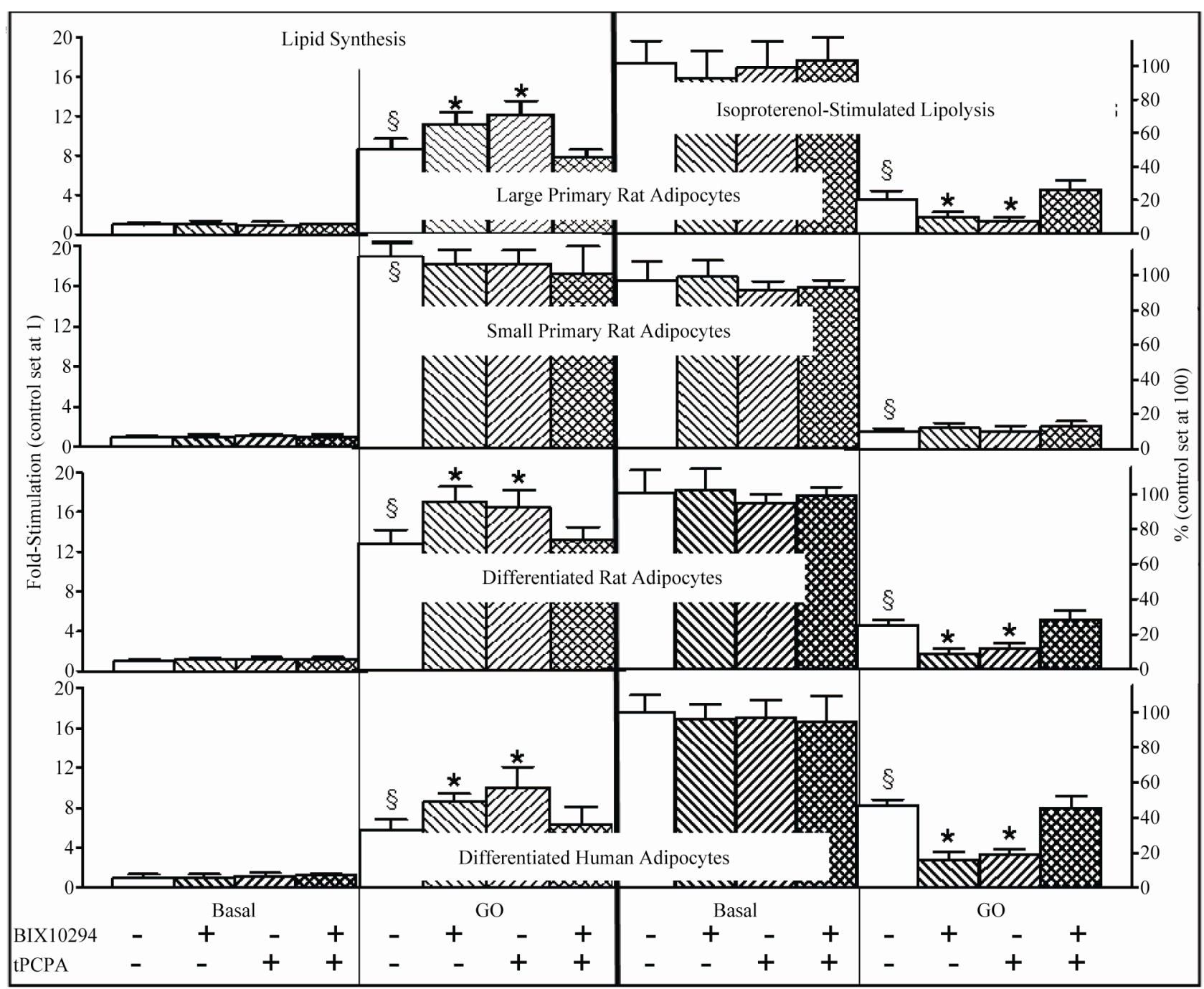

Figure 9. Effects of BIX01294 and tPCPA on the basal and induced lipid synthesis and isoproterenol-stimulated lipolysis in rat and human adipocytes. Large and small primary rat adipocytes or adipocytes differentiated from rat SVCs and human MSCs (identical numbers per well for each adipocyte type) were incubated $\left(70 \mathrm{~h}, 37^{\circ} \mathrm{C}\right)$ in 12-well plates in the absence (control; open bars) or presence (treated; hatched bars) of BIX01294 $(30 \mu \mathrm{M})$ or/and tPCPA $(100 \mu \mathrm{M})$ as indicated. Thereafter, the incubation was continued in the absence (basal) or presence (induced) of GO $(0.5 \mathrm{U} / \mathrm{ml})$ for $20 \mathrm{~h}$. The adipocytes were washed and then assayed for lipid synthesis $(1 \mathrm{~h})$ or isoproterenol-stimulated lipolysis $(2 \mathrm{~h})$ in the absence or presence of GO. Fold-stimulation of lipid synthesis above control (set at 1 for basal adipocytes of each type) and \% of isoproterenol-stimulated lipolysis (set at 100 for basal adipocytes of each type) are given as means \pm S.D. derived from three to five different adipocyte preparations/differentiations with incubations in duplicate (lipid synthesis) and quadruplicate (lipolysis), each. Significant differences between the GO-induced and basal control adipocytes are indicated by ${ }^{\S}$ for each type and between the treated and control (basal or GO-induced) adipocytes by ${ }^{*}$ for each type.

late whereas the inducers upregulate the release of EMVs (Figures 3-6), and 3) BIX01294 and tPCPA apparently do not interfere with the cellular energy charge as reflected in the unaltered insulin regulation of lipid metabolism (Figure 1) argue against a causal link between apoptotic rate and EMV release and its modulation by BIX01294 and tPCPA. Rather it is reasonable to assume that alterations in the histone $\mathrm{H} 3$ methylation state provoked by inhibition of G9a and LSD1 mediates the downregulation of EMV release from rat and human adipocytes.
The promoters and genes that are apparently affected by the altered histone $\mathrm{H} 3$ methylation and that control the release of EMVs from adipocytes remain to be identified. The present findings that BIX01294 and tPCPA always lead to the concerted blockade of the incorporation into EMVs of specific GPI-anchored proteins, mRNAs and miRNAs argue for mechanistic coupling of the biogenetic pathways for these EMV components that encompass the molecular mechanisms for decoding of the corresponding targeting signals. It may be of relevance that the two EMV subpopulations, exosomes and 
microvesicles, seem to use similar or even identical pathways of their biogenesis based on the following observations: 1) Exosomal proteins and phospholipids can bud directly from the plasma membranes of the donor

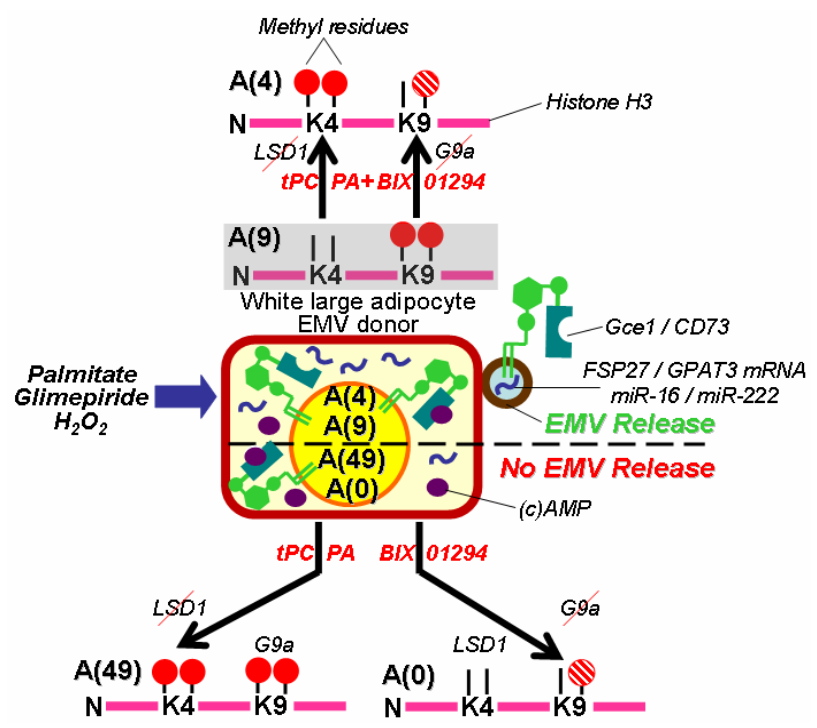

Figure 10. Hypothetical model for the role of the histone $\mathrm{H} 3$ methylation state on the induced release of EMVs harbouring specific RNAs and GPI-anchored proteins from adipocytes. $\mathbf{A ( 9 )}$ In course of preparation and long-term incubation (in the absence of BIX01294 or tPCPA) of large primary or differentiated rat and human adipocytes, histone $\mathrm{H} 3$ remains in the dimethylated K9 and unmethylated K4 "initial" states (grey area). "Overall", this (i.e. "inactivating" K4 plus "inactivating" K9me2) $\mathrm{H} 3$ methylation state results in inactive heterochromatin that supports (basal and induced) EMV release (Figures 3-6). A(0) In the presence of BIX01294 alone, inhibition of the histone methyltransferase, G9a, causes conversion of H3K9me2 into H3K9me1/H3K9 (hatched circle) through constitutive demethylation. A(49) In the presence of tPCPA alone, inhibition of the histone lysine demethylase, LSD1, leads to elevated levels of $\mathrm{H} 3 \mathrm{~K} 4 \mathrm{me} 2$ through constitutive methylation. "Overall", these two (i.e. "inactivating" $\mathrm{H} 3 \mathrm{~K} 4$ plus [partially] "activating" $\mathrm{H} 3-$ K9me1 and "activating" H3K4me2 plus inactivating" H3K9me2) H3 methlylation states result in partially open active euchromatin that is not compatible with (basal and induced) EMV release (Figures 3-6). A(4) In the presence of both BIX01294 and tPCPA, the simultaneous inhibition of G9a and LSD1 leads to (partial) demethylation of $\mathrm{H} 3 \mathrm{~K} 9 \mathrm{me} 2$ and complete methylation of H3K4. "Overall", this (i.e. "activating" H3K4me2 plus [partially] "activating" H3K9[me1]) H3 methylation state results in completely open "superactive" euchromatin that supports EMV release (Figures 3-6). In conclusion, primary (in particular large) and differentiated rat and human adipocytes with the H3 methylation states A(9) (initial) or A(4) (BIX01294 plus tPCPA), but not A(0) (BIX01294) or A(49) (tPCPA) apparently respond toward physiological concentrations of palmitate and $\mathrm{H}_{2} \mathrm{O}_{2}$ or pharmacological concentrations of glimepiride with the release of transcripts specific for FSP27 (Figure 4(a)), GPAT3 (Figure 4(b)), miR-16 (Figure 5) and miR-222 (Figure 6) into the lumen as well as of the GPI-anchored proteins, Gcel (Figure 3(a)) and CD73 (Figure 3(b)), into the outer membrane leaflet, respectively, of EMVs (Figure 10). cells [71]. 2) The formation of multivesicular bodies requires the ESCRT (Endosomal Sorting Complexes Required for Transport) machinery [72], whereas microvesicle and, in contrast to previous assumptions, also exosome biogenesis does not [71]. This argues for identical multivesicular body-independent biogenetic pathways for the two EMV subpopulations. 3) Exosomes are detectable as deep invaginations of plasma membranes and thus possibly share the site of biogenesis with that of microvesicles [73]. However, our current understanding of EMV biogenesis is rudimentary and little is known about the signals that target proteins and RNAs to the site(s) of EMV release. Concerning the protein constituents, recently reported data suggest that several different types of plasma membrane anchors and signals manage to direct highly oligomeric cytoplasmic polypeptides to the site(s) of EMV release. Among them are N-terminal acylation or myristoylation tags, internal phosphatidylinositol-(3,)4,5-bisphosphate-binding domains and C-terminal prenylation and palmitoylation tags as well as type-I integral plasma membrane inner leaflet and GPI plasma membrane outer leaflet targeting domains $[13,72$, 73]. With regard to GPI-anchored proteins, their segregation into the site(s) of EMV release may be based on the intrinsic capability of GPI anchors to insert, accumulate and aggregate in lipid rafts of the outer plasma membrane leaflet $[74,75]$. Concerning the RNA constituents, nothing is known about the signals for their targeting into EMVs. It is conceivable that the genes and components engaged in the EMV release from adipocytes and controlled by the histone $\mathrm{H} 3$ methylation state of the corresponding promoters are involved in the plasma membrane inner/outer leaflet targeting and oligomerization/ aggregation of the constituent proteins as well as in the coupled segregation and packaging of the constituent RNAs into the EMVs.

The putative functional consequences of the apparent epigenetic regulation of the induced (by fatty acids, oxidative stress, glimepiride) EMV release for large and small adipocytes within an adipose tissue depot, as can be deduced from the presented and previous in vitro data, are depicted in the following model (Figure 11). The validity of this working model has to be examined in appropriate in vitro and in vivo test systems that enable monitoring of adipocyte hypertrophy in response to (supra)physiological concentrations of palmitate and reactive oxygen species or pharmacological concentrations of glimepiride. Regarding in vitro testing, the induced transfer of the lipogenic information encoded by Gce1/CD73harbouring EMVs from large donor to small acceptor adipocytes and the resulting increase in LD biogenesis and size of the acceptor adipocytes have been demonstrated recently.

For this mixtures of large and small primary rat adi- 
pocytes in suspension as well as partially digested rat epididymal adipose tissue pieces consisting of mixed populations of large and small adipocytes were used for short-term incubations $[27,28]$. These test systems have to be adapted for long-term culturing in order for manifestation of altered histone $\mathrm{H} 3$ methylation states in primary and differentiated adipocytes. Long-term incubation with BIX01294 and IPCPA will then elucidate putative interference with the release of EMVs. Moreover, short-term treatment with (c)AMP-Sepharose or di-annexin will reveal eventual inhibition of fusion of the EMVs with and their action on white adipocytes, i.e. upregulation of cell size and LD biogenesis and transformation into brown or "brite" adipocytes. Regarding in vivo testing, long-term administration to rats fed a highfat diet or exposed to oxidative stress of BIX01294 and tPCPA, provided they display favorable pharmacokinetic profiles, may be useful to study the link between histone H3 methylation and the morphology and function of adipose tissues in intact organisms. On the basis of the present and previous findings the putative consequences of physiological or pharmacological interference with the release of EMVs from large donor adipocytes or/and their fusion with small acceptor adipocytes within adipose tissue depots can be predicted (Table 2). So far, only a limited number of effector molecules and tool compounds are known that modulate EMV release or fusion $[27,28,76]$, among them the anti-diabetic sulfonylurea drug, glimepiride. Glimepiride apparently causes a balance between the elevated release of EMVs from large donor adipocytes thereby triggering downregula- tion of LD biogenesis and the subsequent elevated fusion of the EMVs with small acceptor adipocytes (as a consequence of "mass action" and per se unaffected by the drug $[6,25])$ thereby triggering upregulation of LD biogenesis. Thus "overall", glimepiride treatment should not result in gross "net" alterations in size distribution and LD biogenesis/lipolysis of the adipocytes within adipocyte tissue depots. This seems to be reflected in clinical reports about prolonged treatments of type II diabetic patients with glimepiride that led to only slight increases in total body weight $[77,78]$.

In conclusion and based on the above findings, it is tempting to speculate that for pharmacotherapy of obesity inhibition of EMV fusion alone or in combination with stimulation of EMV release represents a promising option with the benefits of 1) downregulation of LD biogenesis, 2) upregulation of lipolysis, 3) reduction in adipocyte size (Table 2), and 4) transformation of white into "brown adipose tissue-like" adipocytes with accompanying stimulation of energy expenditure [79-81], in particular if the obese state is driven by exposure of adipose tissue depots to excess of fatty acids or oxidative stress (Figure 11). The realization of this novel antiobesity strategy will require the identification of the molecular mechanisms and components underlying the release and fusion of EMVs within adipose tissue depots.

\section{ACKNOWLEDGEMENTS}

All authors are employees of Sanofi Deutschland GmbH. The authors declare no conflict of interest. The design of the experiments, interpre

Table 2. Predicted consequences of the pharmacological interference (inhibition $\downarrow$, stimulation $\uparrow$, no net effect $\leftrightarrow$ ) with the release or/ and fusion of EMVs on LD biogenesis, lipolysis and the ratio between large and small adipocytes (decrease $\downarrow$, increase $\uparrow$, no net alteration $\leftrightarrow$ ) within adipose tissue depots.

\begin{tabular}{|c|c|c|c|c|c|}
\hline Mechanism & Interference & LD Biogenesis & Lipolysis & Large: Small Cells & Effectors Tools \\
\hline \multirow[b]{2}{*}{ EMV Release } & $\downarrow$ & $\uparrow$ & $\downarrow$ & $\uparrow$ & $\begin{array}{l}\text { BIX01294 } \\
\text { tPCPA }\end{array}$ \\
\hline & $\uparrow$ & $\leftrightarrow$ & $\leftrightarrow$ & $\leftrightarrow$ & $\begin{array}{c}\text { Palmitate } \\
\text { Glimepiride } \\
\mathrm{H}_{2} \mathrm{O}_{2}\end{array}$ \\
\hline \multirow[t]{2}{*}{ EMV Fusion } & $\downarrow$ & $\downarrow$ & $\uparrow$ & $\downarrow$ & $\begin{array}{c}\text { cAMP- } \\
\text { Sepharose } \\
\text { Di-Annexin }\end{array}$ \\
\hline & $\uparrow$ & $\uparrow$ & $\downarrow$ & $\uparrow$ & \\
\hline EMV Release + EMV Fusion & $\begin{array}{l}\downarrow \\
\downarrow\end{array}$ & $\leftrightarrow$ & $\leftrightarrow$ & $\leftrightarrow$ & \\
\hline EMV Release + EMV Fusion & $\begin{array}{l}\downarrow \\
\uparrow\end{array}$ & $\uparrow \uparrow$ & $\downarrow \downarrow$ & $\uparrow \uparrow$ & \\
\hline EMV Release + EMV Fusion & $\begin{array}{l}\uparrow \\
\uparrow\end{array}$ & $\leftrightarrow$ & $\leftrightarrow$ & $\leftrightarrow$ & \\
\hline EMV Release + EMV Fusion & $\uparrow$ & $\downarrow \downarrow$ & $\uparrow \uparrow$ & $\downarrow \downarrow$ & \\
\hline
\end{tabular}




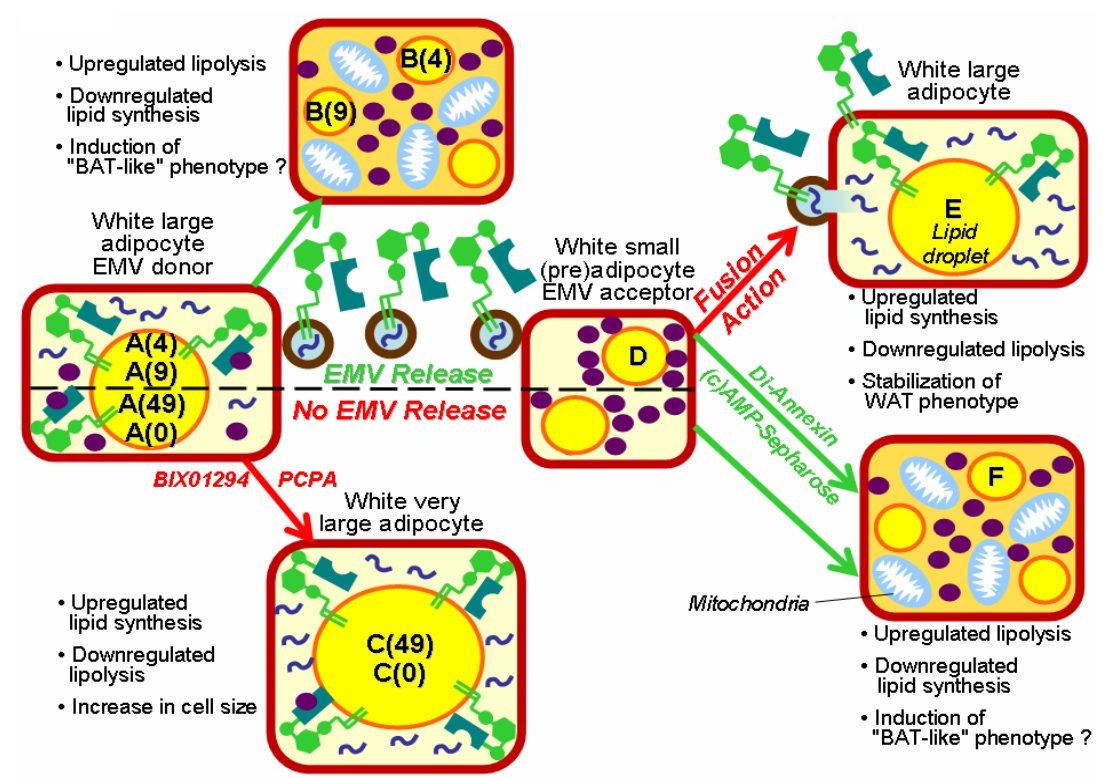

Figure 11. Hypothetical model for the para-/endocrine regulation of lipid metabolism between large and small rat adipocytes by EMVs harbouring specific RNAs and GPIanchored proteins and their epigenetically controlled release. $\mathbf{A ( 4 ) / A ( 9 )}$ White large donor adipocytes release EMVs harbouring the GPI-anchored proteins, CD73 and Gce1, mRNAs specific for GPAT3 and FSP27 and the miRNAs, miR-16 and miR-222. $\mathbf{B}(4) / \mathbf{B}(9)$ The loss of these EMV components from the large donor adipocytes leads to upregulation of lipolysis (in course of increased levels of cAMP at the LD surface zone) and downregulation of lipid synthesis (in course of decreased levels of GPAT3 and FSP27 proteins), that trigger degradation of LDs and eventually induction of the brown adipose tissue-like phenotype [77]. A(49)/A(0) The release of these EMVs from the large donor adipocytes is blocked by modulation of their histone $\mathrm{H} 3$ methylation state (e.g. in course of G9a or LSD 1 inhibition). $\mathbf{C ( 4 9 ) / C ( 0 )}$ The retention of these EMV components in the large donor adipocytes supports downregulation of lipolysis (in course of decreased levels of cAMP at the LD surface zone) and upregulation of lipid synthesis (in course of increased levels of GPAT3 and FSP27) that lead to LD biogenesis and elevation of cell size. (D) The EMVs fuse preferentially with the plasma membranes of white small acceptor (pre)adipocytes. (E) Thereby, the EMVs transfer the GPAT3-/FSP27-specific mRNAs and miR-16/222 miRNAs into the cytoplasm and the CD73/ Gcel GPI-anchored proteins onto the LD surface of the acceptor adipocytes. As a consequence, GPAT3 and FSP27 protein expression becomes upregulated in parallel with degradation of (c)AMP at the LD surface zone, resulting in direct stimulation of lipid synthesis and inhibition of lipolysis. The consequent promotion of LD biogenesis drives the increase in cell size of the (initially small) adipocytes and contributes to the stabilization of their white adipose tissue phenotype. (F) Upon blockade of the release of the EMVs from white large donor adipocytes (as provoked experimentally by BIX01294 or tPCPA) or of their transfer to and fusion with the plasma membranes of white small acceptor adipocytes (as provoked experimentally by [c]AMP-Sepharose [27,28] or di-annexin [76]), the lack of upregulation of FSP27 and GPAT3 protein expression in concert with elevated levels of cAMP at the LD surface zone fosters lipolysis and impairs lipid synthesis in connection to stimulation and inhibition of the biogenesis of mitochondria and LDs, respectively, as well as induction of the brown adipose tissue-like phenotype [82].

tation of the data and writing of the manuscript were not initiated and not affected by the company. This study was supported by Sanofi Deutschland GmbH.

\section{REFERENCES}

[1] Rosen, E.D. and Spiegelman, B.M. (2000) Molecular regulation of adipogenesis. Annual Review of Cell and Developmental Biology, 16, 145-171. doi:10.1146/annurev.cellbio.16.1.145

[2] Müller, G., Wied, S., Dearey, E.-A., Wetekam, E.-A. and Biemer-Daub, G. (2010) Lipid storage in large and small rat adipocytes by vesicle-associated glycosylphosphatidylinositol-anchored proteins. Results and Problems in Cell Differentiation-Sensory and Metabolic Control of En- 
ergy Balance, 52, 27-34. doi:10.1007/978-3-642-14426-4_3

[3] Aoki, N., Jin-no, S., Nakagawa, Y., Asai, N., Arakawa, E., Tamura, N., Tamura T. and Matsuda, T. (2007) Identification and characterization of microvesicles secreted by 3T3-L1 adipocytes: Redox- and hormone-dependent induction of milk fat globule-epidermal growth factor 8associated microvesicles. Endocrinology, 148, 3850-3862. doi:10.1210/en.2006-1479

[4] Ogawa, R., Tanaka, C., Stao, M., Nagasaki, H., Sugimura, K., Okumura, K., Nakagawa, Y. and Aoki N. (2010) Adipocyte-derived microvesicles contain RNA that is transported into macrophages and might be secreted into blood circulation. Biochemical and Biophysical Research Commununication, 398, 723-729.

doi:10.1016/j.bbrc.2010.07.008

[5] Müller, G., Jung, C., Straub, J. and Wied, S. (2009) Induced release of membrane vesicles and exosomes from rat adipocytes containing lipid droplet, lipid raft and glycosylphosphatidylinositol-anchored proteins. Cellular Signaling, 21, 324-338. doi:10.1016/j.cellsig.2008.10.021

[6] Müller, G., Jung, C., Wied, S. and Biemer-Daub, G. (2009) Induced translocation of glycosylphosphatidylinositolanchored proteins from lipid droplets to adiposomes in rat adipocytes. British Journal of Pharmacology, 158, 749770. doi:10.1111/j.1476-5381.2009.00360.x

[7] Müller, G. (2010) Control of lipid storage and cell size between adipocytes by vesicle-associated glycosylphosphatidylinositol-anchored proteins. Archives of Physiology and Biochemistry, 117, 23-43. doi:10.3109/13813455.2010.513393

[8] Goichot, B., Grunebaum, L., Desprez, D., Vinzio, S., Meyer, L., Schlienger, J.L., Lessard, G. and Simon, C. (2006) Circulating procoagulant microparticles in obesity. Diabetes and Metabolism, 32, 82-85. doi:10.1016/S1262-3636(07)70251-3

[9] Leroyer, A.S., Tedgui, A. and Boulanger, C.M. (2008) Microparticles and type 2 diabetes. Diabetes and $\mathrm{Me}$ tabolism, 34, S27-S31. doi:10.1016/S1262-3636(08)70100-9

[10] Cocucci, E., Racchetti, G. and Meldolesi, J. (2008) Shedding microvesicles: artefacts no more. Trends in Cell Biology, 19, 43-51. doi:10.1016/j.tcb.2008.11.003

[11] Piccin, A., Murphy, W.G. and Smith, O.P. (2007) Circulating microparticles: pathophysiology and clinical implications. Blood Reviews, 21, 157-171. doi:10.1016/j.blre.2006.09.001

[12] Simons, M. and Raposo, G. (2009) Exosomes-vesicular carriers for intercellular communication. Current Opinion in Cell Biology, 21, 575-581. doi:10.1016/j.ceb.2009.03.007

[13] Shen, B., Wu, N., Yang, Jr.M. and Gould, S.J. (2011) Protein targeting to exosomes/microvesicles by plasma membrane anchors. Journal of Biological Chemistry, 286, 14383-14395. doi:10.1074/jbc.M110.208660

[14] Valadi, H., Ekström, K., Bossios, A., Sjöstrand, M., Lee, J.J. and Lötvall, J.O. (2007) Exosome-mediated transfer of mRNAs and microRNAs is a novel mechanism of genetic exchange between cells. Nature Cell Biology, 9,
654-659. doi:10.1038/ncb1596

[15] Camussi, G., Deregibus, M.C., Bruno, S., Cantaluppi, V. and Biancone, L. (2010) Exosomes/microvesicles as a mechanism of cell-to-cell communication. Kidney International, 78, 838-848. doi:10.1038/ki.2010.278

[16] Al-Nedawi, K., Meehan, B., Kerbel, R.S., Allison, A.C. and Rak, J. Endothelial expression of autocrine VEGF upon the uptake of tumor-derived microvesicles containing oncogenic EGFR. Proceedings of the National Academy of Sciences USA, 106, 3794-3799. doi:10.1073/pnas.0804543106

[17] Castellana, D., Toti, F. and Freyssinet, J.M. (2010) Membrane microvesicles: Macromessengers in cancer disease and progression. Thrombosis Research, 125, S84-S88. doi:10.1016/S0049-3848(10)70021-9

[18] Yuan, A., Farber, E.L. and Rapoport, A.L. (2009) Transfer of microRNAs by embryonic stem cell microvesicles. PLoS One, 4, e4722. doi:10.1371/journal.pone.0004722

[19] Heneghan, H.M., Miller, N. and Kerin, M.J. (2009) Role of microRNAs in obesity and the metabolic syndrome. Obesity Reviews, 11, 354-361. doi:10.1111/j.1467-789X.2009.00659.x

[20] Lin, Q., Gao, Z., Alarcon, R.M., Ye, J. and Yun, Z. (2009) A role of miR-27 in the regulation of adipogenesis. FEBS Journal, 276, 2348-2358. doi:10.1111/j.1742-4658.2009.06967.x

[21] Esau, C., Kang, X., Peralta, E., Hanson, E., Marcusson, E.G., Ravichandran, L.V., Sun, Y., Koo, S., Perera, R.J., Jain, R., Dean, N.M., Freier, S.M., Bennet, C.F., Lollo, B. and Griffey, R. (2004) MicroRNA-143 regulates adipocyte differentiation. Journal of Biological Chemistry, 279, 52361-52365. doi:10.1074/jbc.C400438200

[22] Xie, H., Lim, B. and Lodish, H.F. (2009) MicroRNAs induced during adipogenesis that accelerate fat cell development are downregulated in obesity. Diabetes, $\mathbf{5 8}$, 1050-1057. doi:10.2337/db08-1299

[23] Ortega, F.J., Moreno-Navarrete, J.M., Pardo, G., Sabater, M., Hummel, M.; Ferrer, A., Rodriguez-Hermosa, J.I., Ruiz, B., Ricart, W., Pera, B. and Fernandez-Real, J.M. (2010) miRNA expression profile of human subcutaneous adipose and during adipocyte differentiation. PLoS One, 5, e9022. doi:10.1371/journal.pone.0009022

[24] Müller, G., Schneider, M., Biemer-Daub, G. and Wied, S. (2011) Microvesicles released from rat adipocytes and harboring glycosylphosphatidylinositol-anchored proteins transfer RNA stimulating lipid synthesis. Cellular Signaling, 23, 1207-1223. doi:10.1016/j.cellsig.2011.03.013

[25] Müller, G., Wied, S., Jung, C., Biemer-Daub, G. and Frick, W. (2010) Transfer of glycosylphosphatidylinositol-anchored 5'-nucleotidase CD73 from adiposomes into rat adipocytes stimulates lipid synthesis. British Journal of Pharmacology, 160, 878-891. doi:10.1111/j.1476-5381.2010.00724.x

[26] Müller, G., Wied, S., Jung, C., Frick, W. and Biemer-Daub, G. (2010) Inhibition of lipolysis by adiposomes containing glycosylphosphatidylinositol-anchored Gcel protein in rat adipocytes. Archives of Physiology and Biochemistry, 116, 28-41. doi:10.3109/13813450903508812 
[27] Müller, G., Wied, S., Dearey, E.-A. and Biemer-Daub, G. (2011) Glycosylphosphatidylinositol-anchored proteins coordinate lipolysis inhibition between large and small adipocytes. Metabolism, 60, 1021-1037. doi:10.1016/j.metabol.2010.10.007

[28] Müller, G., Wied, S. and Schneider, M. (2011) Regulation of lipid synthesis between large and small rat adipocytes by glycosylphosphatidylinositol-anchored CD73. Obesity, 19, 1531-1544. doi:10.1038/oby.2011.29

[29] Müller, G., Over, S., Wied, S. and Frick, W. (2008) Association of (c)AMP-degrading glycosylphosphatidylinositol-anchored proteins with lipid droplets is induced by palmitate, $\mathrm{H}_{2} \mathrm{O}_{2}$ and the sulfonylurea drug, glimepiride, in rat adipocytes. Biochemistry, 47, 12774-12787. doi:10.1021/bi7022915

[30] Müller, G., Wied, S., Jung, C. and Over, S. (2008) Hydrogen peroxide-induced translocation of glycolipid-anchored (c)AMP-hydrolases to lipid droplets mediates inhibition of lipolysis in rat adipocytes. British Journal of Pharmacology, 154, 901-913. doi:10.1038/bjp.2008.146

[31] Müller, G., Wied, S., Jung, C. and Straub, J. (2008) Coordinated regulation of esterification and lipolysis by palmitate, $\mathrm{H}_{2} \mathrm{O}_{2}$ and the anti-diabetic sulfonylurea drug, glimepiride, in rat adipocytes. European Journal of Pharmacology, 597, 6-18. doi:10.1016/j.ejphar.2008.08.034

[32] Cao, J., Li, J.L., Li, D., Tobin, J.F. and Gimeno, R.E. (2006) Molecular identification of microsomal acyl- CoA: glycerol-3-phosphate acyltransferase, a key enzyme in de novo triacylglycerol synthesis. Proceedings of the $\mathrm{Na}$ tional Academy of Sciences USA, 103, 19695-19700. doi:10.1073/pnas.0609140103

[33] Nishino, N., Tamori, Y., Tateya, S., Kawaguchi, T. and Shibakusa, T. (2008) FSP27 contributes to efficient energy storage in murine white adipocytes by promoting the formation of unilocular lipid droplets. Journal of Clinical Investigation, 118, 2808-2821. doi:10.1172/JCI34090

[34] Puri, V., Ranjit, S., Konda, S., Nicoloro, S.M., Straubhaar, J., Chawla, A., Chouinard, M., Lin, C., Burkart, A., Corvera, S., Perugini, R.A. and Czech, M.P. (2008) Cidea is associated with lipid droplets and insulin sensitivity in humans. Proceedings of the National Academy of Sciences USA, 105, 7833-7838. doi:10.1073/pnas.0802063105

[35] Heerwagen, M.J.R., Miller, M.R., Barbour, L.A. and Friedman, J.E. (2010) Maternal obesity and fetal metabolic programming: A fertile epigenetic soil. American Journal of Physiology Regulatory, Integrative and Comparative Physiology, 299, R711-R722. doi:10.1152/ajpregu.00310.2010

[36] Stöger, R. (2008) Epigenetics and obesity. Pharmacogenomics, 9, 1851-1860. doi:10.2217/14622416.9.12.1851

[37] Jenuwein, T. and Allis, C.D. (2001) Translating the histone code. Science, 293, 1074-1080. doi:10.1126/science.1063127

[38] Schreiber, S.L. and Bernstein, B.E. (2002) Signaling network model of chromatin. Cell, 111, 771-778. doi:10.1016/S0092-8674(02)01196-0

[39] Martin, C. and Zhang, Y. (2005) The diverse functions of histone lysine modification. Nature Reviews Molecular

\section{Cell Biology, 6, 838-849. doi:10.1038/nrm1761}

[40] Campion, J., Milagro, F.I. and Martinez, J.A. (2009) Individuality and epigenetics in obesity. Obesity Reviews, 10, 383-392. doi:10.1111/j.1467-789X.2009.00595.x

[41] Parra, P., Serra, F. and Palou, A. (2010) Expression of adipose microRNAs is sensitive to dietary conjugated linoleic acid treatment in mice. PLoS One, 5, e13005. doi:10.1371/journal.pone.0013005

[42] Sommerfeld, M., Müller, G., Tschank, G., Seipke, G., Habermann, P., Kurrle, R. and Tennagels, N. (2010) In vitro metabolic and mitogenic signaling of insulin glargine and its metabolites. PLoS One, 5, e9540. doi:10.1371/journal.pone.0009540

[43] Geisen, K. (1988) Special pharmacology of the new sulfonylurea glimepiride. Drug Research, 38, 1120-1130.

[44] Müller, G., Ertl, J., Gerl, M. and Preibisch, G. (1997) Leptin impairs metabolic actions of insulin in isolated rat adipocytes. Journal of Biological Chemistry, 272, 1058510593. doi:10.1074/jbc.272.16.10585

[45] Frick, W., Bauer, A., Bauer, J., Wied, S. and Müller, G. (1998) Structure-activity relationship of synthetic phosphoinositolglycans mimicking metabolic insulin action. Biochemistry, 37, 13421-13436. doi:10.1021/bi9806201

[46] Müller, G., Wied, S., Over, S. and Frick, W. (2008) Inhibition of lipolysis by palmitate, $\mathrm{H}_{2} \mathrm{O}_{2}$ and the sulfonylurea drug, glimepiride, in rat adipocytes depends on cAMP degradation by lipid droplets. Biochemistry, 47, 1259-1273. doi:10.1021/bi701413t

[47] Müller, G., Wied, S., Walz, N. and Jung, C. (2008) Translocation of glycosylphosphatidylinositol-anchored proteins from plasma membrane microdomains to lipid droplets in rat adipocytes is induced by palmitate, $\mathrm{H}_{2} \mathrm{O}_{2}$ and the sulfonylurea drug, glimepiride. Molecular Pharmacology, 73, 1513-1529. doi:10.1124/mol.107.043935

[48] Miranville, A., Herling, A.W., Biemer-Daub, G. and Voss, M.D. (2010) Reversal of inflammation-induced impairment of glucose uptake in adipocytes by direct effect of CB1 antagonism on adipose tissue macrophages. Obesity, 18, 2247-2254. doi:10.1038/oby.2010.81

[49] Rodbell, M. (1964) Metabolism of isolated fat cells. I. Effects of hormones on glucose metabolism and lipolysis. Journal of Biological Chemistry, 239, 375-380.

[50] Sugihara, H., Yonemitsu, N., Miyabara, S. and Yun, K. (1986) Primary culture of unilocular fat cells: Characteristics of growth in vitro and changes in differentiation properties. Differentiation, 31, 42-49. doi:10.1111/j.1432-0436.1986.tb00381.x

[51] Zhang, H.H., Kumar, S., Barnett, A.H. and Eggo, M.C. (2000) Ceiling culture of mature human adipocytes: Use in studies of adipocyte functions. Journal of Endocrinology, 164, 119-128. doi:10.1677/joe.0.1640119

[52] Linscheid, P., Seboek, D., Zulewski, H., Keller, U. and Müller, B. (2000) Autocrine/paracrine role of inflammation-mediated calcitonin gene-related peptide and adrenomedullin expression in human adipose tissue. Endocrinology, 146, 2699-2708. doi:10.1210/en.2004-1424

[53] Tchkonia, T., Giorgadze, N., Pirtskhalava, T., Tchoukalova, Y., Karagiannides, I., Forse, R.A., Deponte, M., 
Stevenson, M., Guo, W., Han, J., Waloga, G., Lash, T.L., Jensen, M.D. and Kirkland, J.K. (2002) Fat depot origin affects adipogenesis in primary cultured and cloned human preadipocytes. Americal Journal of Physiology Regulatory, Integrative and Comparative Physiology, 282, R1286-R1296. doi:10.1152/ajpregu.00653.2001

[54] Müller, G. and Wied, S. (1993) The sulfonylurea drug, glimepiride, stimulates glucose transport, glucose transporter translocation, and dephosphorylation in insulinresistant rat adipocytes in vitro. Diabetes, 42, 1852-1867. doi:10.2337/diabetes.42.12.1852

[55] Müller, G., Jordan, H., Petry, S., Wetekam, E.-M. and Schindler, P. (1997) Analysis of lipid metabolism in adipocytes using fluorescent fatty acids. I. Insulin stimulation of lipogenesis. Biochimica et Biophysica Acta, 1347, 23-39. doi:10.1016/S0005-2760(97)00044-1

[56] Jenuwein, T. (2006) The epigenetic magic of histone lysine methylation. FEBS Journal, 273, 3121-3135. doi:10.1111/j.1742-4658.2006.05343.x

[57] Cole, P.A. (2008) Chemical probes for histone-modifying enzymes. Nature Chemical Biology, 4, 590-597. doi:10.1038/nchembio.111

[58] Spannhoff, A., Hauser, A.T., Heinke, R., Sippl, W. and Jung, M. (2009) The emerging therapeutic potential of histone methyltransferase and demethylase inhibitors. ChemMedChem, 4, 1568-1582. doi:10.1002/cmdc.200900301

[59] Shi, Y., Lan, F., Matson, C., Mulligan, P., Whetstine, J.R., Cole, P.A., Casero, R.A. and Shi, Y. (2004) Histone demethylation mediated by the nuclear amine oxidase homolog LSD1. Cell, 119, 941-953. doi:10.1016/j.cell.2004.12.012

[60] Huang, Y., Greene, E., Stewart, T.M., Goodwin, A.C., Baylin, S.B., Woster, P.M. and Casero, R.A. (2007) Inhibition of lysine-specific demethylase 1 by polyamine analogues results in reexpression of aberrantly silenced genes. Proceeding of the National Academy of Sciences USA, 104, 8023-8028. doi:10.1073/pnas.0700720104

[61] Kubicek, S., O’Sullivan, R.J., August, E.M., Hickey, E.R., Zhang, Q., Teodoro, M.L., Rea, S., Mechtler, K., Kowalski, J.A., Homon, C.A., Kelly, T.A. and Jenuwein, T. (2007) Reversal of H3K9me2 by a small-molecule inhibitor for the G9a histone methyltransferase. Molecular Cell, 25, 473-481. doi:10.1016/j.molcel.2007.01.017

[62] Chang, Y., Zhang, X., Horton, J.R., Upadhyay, A.K., Spannhoff, A., Liu, J., Snyder, J.P., Bedford, M.T. and Cheng, X. (2009) Structural basis for G9a-like protein lysine methyltransferase inhibition by BIX-01294. Nature Structural Molecular Biology, 16, 312-317. doi:10.1038/nsmb.1560

[63] Yang, M., Culhane, J.C., Szewczuk, L.M., Gocke, C.B., Brautigam, C.A., Tomchick, D.R., Machius, M., Cole, P.A. and $\mathrm{Yu}, \mathrm{H}$. (2007) Structural basis of histone demethylation by LSD1 revealed by suicide inactivation. Nature Structural Molecular Biology, 14, 535-539. doi:10.1038/nsmb1255

[64] Kang, J., Heart, E. and Sung, C.K. (2001) Effects of cellular ATP depletion on glucose transport and insulin signaling in 3T3-L1 adipocytes. American Journal of Physi- ology, Endocrinology and Metabolism, 280, E428-435.

[65] Stimson, L., Rowlands, M.G., Newblatt, Y.M., Smith, N.F., Raynaud, F.I., Rogers, P., Bavetsias, V., Gorsuch, S., Jarman, M., Bannister, A., Kouzarides, T., McDonald, E., Workman, P. and Aherne, G.W. (2005) Isothiazolones as inhibitors of PCAF and p300 histone acetyltransferase activity. Molecular Cancer Therapy, 4, 1521-1532. doi:10.1158/1535-7163.MCT-05-0135

[66] Kijima, M., Yoshida, M., Sugita, K., Horinouchi, S. and Beppu, T. (1993) Trapoxin, an antitumor cyclic tetrapeptide, is an inhibitor of mammalian histone deacetylase. Journal of Biological Chemistry, 268, 22429-22435.

[67] Cheng, X. and Blumenthal, R.M. (2010) Coordinated chromatin control: Structural and functional linkage of DNA and histone methylation. Biochemistry, 49, 29993008. doi:10.1021/bi100213t

[68] Müller, G. (2011) Let's shift lipid burden—from large to small adipocytes. European Journal of Pharmacology, 656, 1-4. doi:10.1016/j.ejphar.2011.01.035

[69] Cho, Y.-W., Hong, S.H., Jin, Q., Wang, L., Lee, J.E., Gavrilova, O. and Ge, K. (2009) Histone methylation regulator PTIP is required for PPAR $\gamma$ and $\mathrm{C} / \mathrm{EBP} \alpha$ expression and adipogenesis. Cell Metabolism, 10, 27-39. doi:10.1016/j.cmet.2009.05.010

[70] Musri, M.M., Carmona, M.C., Hanzu, F.A., Kaliman, P., Gomis, R. and Parrizas, M. (2010) Histone demethylase LSD1 regulates adipogenesis. Journal of Biological Chemistry, 285, 30034-30041. doi:10.1074/jbc.M110.151209

[71] Booth, A.M., Fang, Y., Fallon, J.K., Yang, Y.M., Hildreth, J.E. and Gould, S.J. (2006) Exosomes and HIV Gag bud from endosome-like domains of the $\mathrm{T}$ cell plasma membrane. Journal of Cell Biology, 172, 923935. doi:10.1083/jcb.200508014

[72] Saksena, S., Sun, J., Chu, T. and Emr, S.D. (2007) ESCRTing proteins in the endocytic pathway. Trends in Biochemical Sciences, 32, 561-573. doi:10.1016/j.tibs.2007.09.010

[73] Welsch, S., Keppler, O.T., Habermann, A., Allespach, I., Krijnse-Locker, J. and Krausslich, H.G. (2007) HIV-1 buds predominantly at the plasma membrane of primary human macrophages. PLoS Pathogens, 3, e36. doi:10.1371/journal.ppat.0030036

[74] Zacharias, D.A., Violon, J.D., Newton, A.C. and Tsien, R.Y. (2002) Partitioning of lipid-modified monomeric GFPs into membrane microdomains of live cells. Science, 296, 913-916. doi:10.1126/science.1068539

[75] Leventhal, I., Grzybek, M. and Simons, K. (2010) Greasing their way: Lipid modifications determine protein association with membrane rafts. Biochemistry, 49, 63056316. doi:10.1021/bi100882y

[76] Kuypers, F.A., Larkin, S.K., Emeis, J.J. and Allison, A.C. (2007) Interaction of an annexin V homodimer (Diannexin) with phosphatidylserine on cell surfaces and consequent anti-thrombotic activity. Thrombosis and Haemostasis, 97, 478-486. doi:10.1016/S0005-2760(97)00044-1

[77] Salti, I. (2009) Efficacy and safety of insulin glargine and glimepiride in subjects with type 2 diabetes before, during and after the period of fasting in Ramadan. Diabetes 
Medicine, 26, 1255-1261. doi:10.1111/j.1464-5491.2009.02836.x

[78] Gottschalk, M., Danne, T., Vlajnic, A. and Cara, J.F. (2007) Glimepiride versus metformin as monotherapy in pediatric patients with type 2 diabetes: A randomized, single-blind comparative study. Diabetes Care, 30, 790794. doi: $10.2337 / \mathrm{dc} 06-1554$

[79] Gesta, S., Tseng, Y.H. and Kahn, C.R. (2007) Developmental origin of fat: tracking obesity to its source. Cell, 131, 242-256. doi:10.1016/j.cell.2007.10.004

[80] Frontini, A. and Cinti, S. (2011) Distribution and development of brown adipocytes in the murine and human adipose organ. Cell Metabolism, 11, 352-256. doi:10.1016/j.cmet.2010.03.004

[81] Cinti, S. (2002) Adipocyte differentiation and transdifferentation: Plasticity of the adipose organ. Journal of Endocrinological Investigations, 25, 823-835.

[82] Toh, S.Y., Gong, J., Du, G., Li, J.Z., Yang, S., Ye, J., Yao, H., Zhang, Y., Xue, B. and Li, Q. (2008) Up-regulation of mitochondrial activity and acquirement of brown adipose tissue-like property in the white adipose tissue of fsp27 deficient mice. PLoS One, 3, e2890. doi:10.1371/journal.pone. 0002890 